Review article

\title{
Psychosocial interventions on perinatal depression in China: A systematic review and meta-analysis
}

\author{
Juan Yin ${ }^{\mathrm{a}}$, Anum Nisar ${ }^{\mathrm{b}}$, Ahmed Waqas ${ }^{\mathrm{c}, \mathrm{d}}$, Yan Guo ${ }^{\mathrm{a}}$, Wen Li Qi ${ }^{\mathrm{e}}$, Duolao Wang ${ }^{\mathrm{f}}$, Atif Rahman ${ }^{\mathrm{g}, 1}$, \\ Xiaomei $\mathrm{Li}^{\mathrm{a}, 1, *}$ \\ ${ }^{a}$ School of nursing, Xi'an Jiaotong University, 76 West Yanta Road, 710061 Xi'an, China \\ ${ }^{\mathrm{b}}$ School of Public Health, Xi'an Jiaotong University, Xi'an, China \\ ${ }^{\mathrm{c}}$ Human Development Research Foundation, Rawalpindi, Pakistan \\ ${ }^{\mathrm{d}}$ University of Liverpool, Liverpool, UK \\ e Department of obstetrics, Xi'an Aerospace general hospital, Xi'an, China \\ ${ }^{\mathrm{f}}$ Liverpool School of Tropical Medicine, Liverpool, UK \\ ${ }^{\mathrm{g}}$ Institute of Life and Human Sciences, University of Liverpool, Liverpool, UK
}

\section{A R T I C L E I N F O}

\section{Keywords:}

Perinatal depression

China

Psychosocial interventions

Systematic review and meta-analysis

\begin{abstract}
A B S T R A C T
Background: The prevalence of perinatal depression is $16.3 \%$ in China and has shown a rising trend in the last decade. However, few studies summarized psychosocial interventions for perinatal depression in this country. This study aimed at evaluating and characterizing psychosocial interventions for perinatal depression in Mainland China.

Methods: Ten major English and Chinese language electronic bibliographic databases were searched for RCTs examining the effect of psychosocial interventions for perinatal depressed women in Mainland China. Studies meeting eligibility criteria and published before 25th February 2019 were included, while those focusing on a very specific sub-population or reporting non-psychosocial interventions were excluded. Data was extracted by a standard form. Meta-analysis was conducted to obtain a summary measure of the effectiveness of the interventions in reducing perinatal depressive symptoms. The theoretical underpinnings and implementation processes of the interventions were also characterised.

Results: A total of 6857 articles were identified in the initial database searching, of which, 26 studies were eligible for data analysis, representing a sample size of 4673. Meta-analysis indicated that psychosocial interventions in China significantly reduced perinatal depressive symptoms (standard difference in means $0.81,95 \%$ confidence intervals -1.03 to $-0.58, P<0.001$ ). However, the overall evidence presented substantial heterogeneity $\left(\mathrm{I}^{2}=91.12 \%\right)$. Most interventions were implemented in hospitals in urban areas by non-specialist health care providers. Few studies reported details of implementation procedures or scale-up strategies.

Limitations: The evidence in this review is of moderate to low quality and therefore, should be interpreted with caution. Some of the trials were inadequately powered and tended to overestimate effect sizes.

Conclusions: Current psychosocial interventions in China are somewhat effective in reducing perinatal depressive symptoms. High quality RCTs on scale-up interventions are required, especially in rural areas.
\end{abstract}

\section{Introduction}

Perinatal depression is typically defined as major or mild depressive episodes, which occurs during pregnancy or within 12 months after delivery (Gynecologists, 2018). Associated with a number of cultural, social and economic stressors, pregnancy and the postpartum period put women at a greater risk of depressive disorder (Biaggi et al., 2016).
The prevalence of perinatal depression has been estimated at between $10 \%$ to $15 \%$ in High-Income Countries (HIC) and $19-25 \%$ in Low- and Middle Income countries (LMIC) (Gelaye et al., 2016; Woody et al., 2017).

Untreated perinatal depression is reported to be associated with various adverse health outcomes for the mothers, including poor nutrition, substance misuse, increased obstetric complications and suicide

\footnotetext{
* Corresponding author.

E-mail address: roselee@xjtu.edu.cn (X. Li).

${ }^{1}$ Atif Rahman and Xiaomei Li are joint senior authors
} 
(Bauer et al., 2016; Evans et al., 2001). It has also been linked with impaired health of infants, including poor physical and mental development and increased risk for later common mental disorders in the off spring (Gelaye et al., 2016; Herba et al., 2016; Weissman et al., 2006). Besides, perinatal depression causes a significant medical cost to the family and society. It is estimated that the total lifetime costs of perinatal depression in UK were $£ 75,728$ per woman, aggregating to $£ 6.6$ billion (Bauer et al., 2016).

China, the world's most populous country, has seen remarkable improvement in maternal and infant health indicators in recent decades (Ministry of Foreign Affairs, P. R. C. July, 2015). In contrast, the prevalence of perinatal depression remains high (15-18\%) and has increased during the last decades (Nisar et al. 2019). The high prevalence of perinatal depression indicates an urgent need for interventions in China, particularly psychosocial interventions that are acceptable, feasible and affordable (Richter et al., 2017). There has been some research exploring the management of perinatal depression in China. However, to our knowledge, there are no systematic reviews and metaanalyses providing a synthesis of psychological and psychosocial interventions in mainland China. This report aims to quantize evidence pertaining to effectiveness of psychological and psychosocial interventions for perinatal depression in China. In addition, we also want to summarize and critically evaluate the theoretical underpinnings of these interventions and their implementation processes.

\section{Methods}

We documented the research process following the Preferred Reporting Items for Systematic Reviews and Meta-Analyses (PRISMA) guidelines.

\subsection{Search strategy and selection criteria}

A bilingual team of two researchers systematically searched the following ten English and Chinese language electronic bibliographic databases: Medline, EMBASE, Scopus, CINAHL, PsycINFO, Web of Science, Cochrane Central Register, the China National Knowledge Infrastructure, the VIP Database for Chinese Technical Periodicals, and the Wan Fang Database for Chinese Periodicals, using a pretested search strategy (Appendix Table A1). There was no restriction of publication date and all the studies available from the inception of the databases till 25th February, 2019 were incorporated. The inclusion criteria are as follows:

Participants: Studies focused on pregnant women or women within 12 months after delivery in Mainland China.

Intervention: Studies examining the effect of psychosocial interventions on perinatal depression, either prevention or treatment.

Control: Routine care or blank control.

Outcomes: Measurement and reporting of perinatal depression scores using a validated self-report scale (e.g., EPDS, SDS, PHQ-9) or clinician-administered measure.

Study design: Studies with randomized controlled trials (RCTs) or cluster RCTs design were included.

The exclusion criteria are: Studies with participants from a very specific sub-population (e.g., people with a specific disease or condition or epidemiological character); Studies with insufficient outcome data for meta-analysis. The protocol of this review can be found at https://www.crd.york.ac.uk/prospero/\#record (CRD42018115934).

Duplicate articles were identified using EndNote, and the papers with more complete data were included for repeat publications. Two investigators worked independently screening the titles and abstracts for inclusion, followed by the full-text screening. Manual searching of the bibliography of all included articles was conducted lastly.
Consensus on papers to be included was reached after discussion and a third researcher was involved when necessary.

\subsection{Data extraction}

Two independent reviewers extracted the following information with a standard form based on Cochrane handbook: (1)General information including study design, sample characteristics, geographical setting, details of intervention, type and training of delivery agent, outcome measures; (2)Data for meta-analysis including sample size, primary outcome, effect size; (3)Therapeutic techniques used in the intervention. Risk of bias of individual research was evaluated by two reviewers according to Cochrane risk of bias tool. Differences in data extraction and risk of bias were resolved by discussion between the reviewers and the principle author.

Besides the above information, the psychosocial interventions were thoroughly audited to identify the broader elements and techniques employed in them. For the phase of data extraction, taxonomy of elements of psychosocial interventions employed in common mental problems was adopted after discussion with two psychologists (Singla et al, 2017). The finalized taxonomy included 58 most commonly utilized treatment elements that could be treatment specific or nonspecific. Definitions of therapeutic elements employed in psychosocial interventions are summarized in Appendix Table A2.

\subsection{Meta-analyses}

The effect sizes of individual study were listed by standard difference in means and $95 \%$ confidence intervals (95\% CIs) in a forest plot. A fixed-effect model was used if no statistical difference in heterogeneity was found; otherwise, a random-effect model was adopted. The statistical heterogeneity was quantified by the $\mathrm{I}^{2}$ statistic and formally tested by Cochrane's Q statistic. Publication bias was visually judged by the symmetry of a funnel plot and the result of Egger's linear regression test. Post-hoc sensitivity analyses were performed (using leave-one-out analysis) to test the impact of exclusion of a single trial with a disproportionately large effect. Subgroup analyses were used to explore the sources of heterogeneity according to quality of the study, scale, theoretical orientation, specificity, scope of intervention and elements of interventions. Studies with two or less items ranked as high risk were classified as high quality, otherwise were classified as low quality (Naveed, S. et al, 2019). Scope of intervention was classified as treatment and prevention. Reference to justify perinatal depression had to be defined according to a diagnostic interview based on clinical criteria (CCMD-3, DSM-5 or ICD-10), or as a score above a cut-off on a selfrating depression scale (PHQ-9, SDS, HAMD, et al). Studies focusing on perinatal depressed mothers with a clear diagnosis of "perinatal depression" (based on ICD-10, CCMD-3 or DSM-5) was classified as "treatment". Studies focusing on high risk mothers or mothers without perinatal depression (identified by screening with a validated scale, e.g., EPDS, SDS, PHQ-9, HAMD) was classified as "prevention". Studies focusing on all mothers (without diagnosis or screening for perinatal depression) was classified as others. Statistical significance was set at $\mathrm{P}$ value $<0.05$ (two-tailed test). All the analyses were carried out by the Comprehensive meta-analysis software (version 3, BIOSTATS, 2014).

\section{Results}

A total of 10,311 articles were found through database searching and 3454 duplications were removed. After title and abstract screening, 198 articles were identified eligible for full text screen, and 26 studies were finally included in the data analysis. Study selection process is illustrated as a PRISMA flowchart in Fig. 1.

A total of 26 trials of psychosocial interventions representing a sample size of 4673 perinatal women were included. The age of perinatal women included in the studies ranged from 17 to 45 years old 


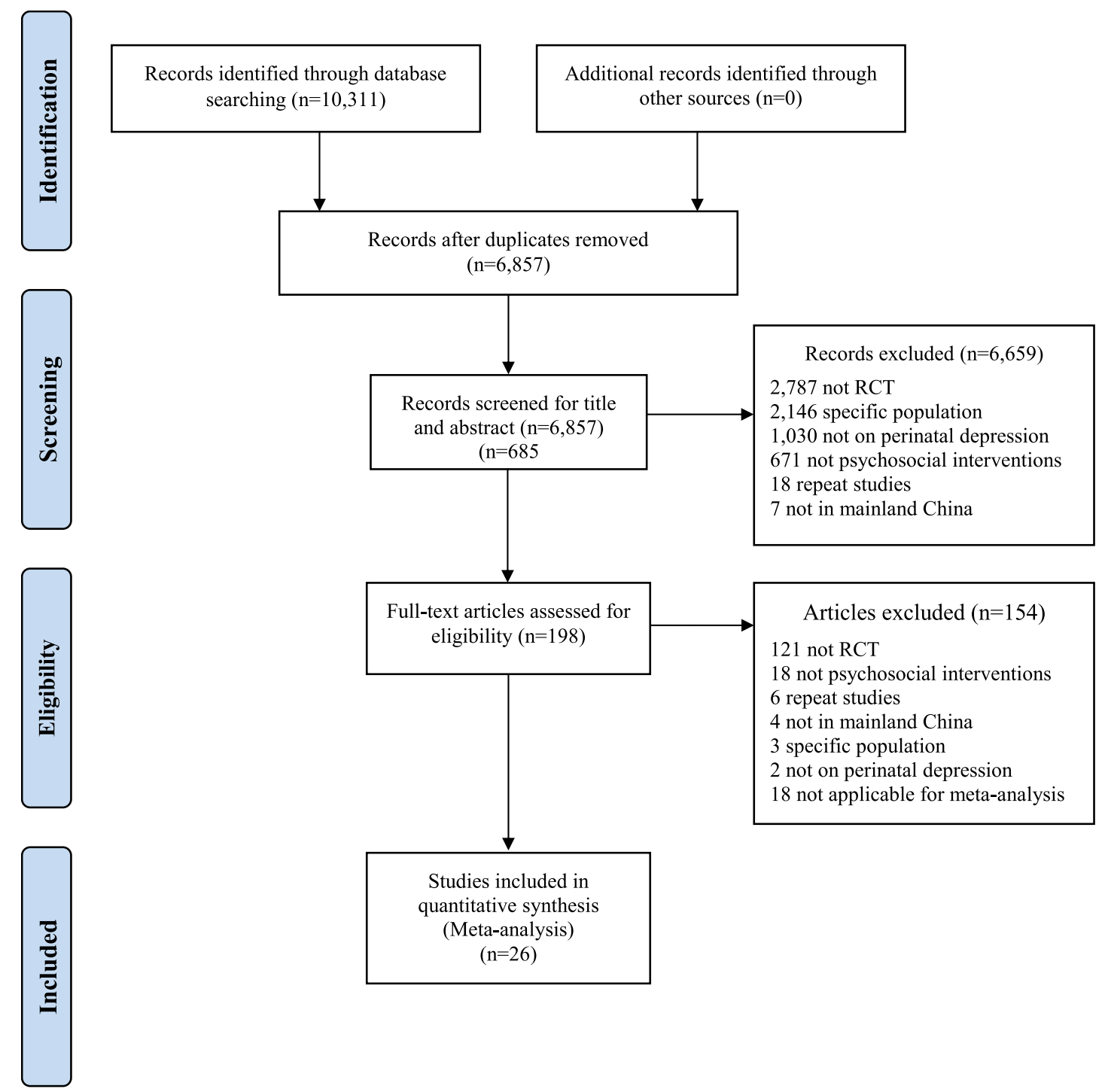

Fig. 1. Study selection process for psychosocial interventions of perinatal depression in women in China.

(29.37 \pm 1.87). For the study design, 25 studies (Cheng et al., 2016; Dou, 2018; Gao et al., 2010; Gao et al., 2015; Guan et al., 2015; Ho et al., 2009; Huang et al., 2015; Jia et al., 2017; Jiang et al., 2014; Leung et al., 2016; Leung and Lam, 2012; Li, 2018; Liu et al., 2012; Liu et al., 2018; Lu and Fan, 2017; Lu et al., 2016; Mao et al., 2012; Ngai et al., 2015; Sun et al., 2011; Wu, 2018; Wu, 2017; Yang et al., 2019; Zhang et al., 2018; Zhang et al., 2016; Zhao, 2018) were RCTs and one (Ngai et al., 2009) reported cluster RCT. Nineteen studies focused on postnatal depression, three on prenatal depression and two on both prenatal and postnatal depression. The most commonly used psychometric scales for assessment of perinatal depression were the Edinburgh Postnatal Depression Scale (14 studies), followed by Zung Self-Rating Depression Scale (six studies), Hamilton depression scale (three studies) and Patient Health Questionnaire-9 (three studies). The primary time point of outcome assessment varied from after intervention to four-month post intervention, with ten studies reported follow-up data. Details can be found in Table 1 and Appendix Table A3.

Regarding to the intervention delivery, 22 studies were conducted in urban areas, two in semi-urban areas, and two did not indicate the research region. All studies delivered the interventions in hospitals or health care centers. The interventions were mostly provided by non-specialist health care workers, with six by nurses, four by midwives, and eight by multidiscipline health care workers (seven studies did not report the delivery agent). As for the type of interventions, 17 studies focused on preventive interventions while the rest on treatment. The duration of overall intervention program varied from one day to eight weeks. Nineteen out of the 26 studies had more than one intervention sessions. Two studies delivered brief interventions-a one-session education program before discharge with a follow-up session (Gao et al., 2015; Ho et al., 2009). Five studies did not report detailed information regarding to the duration or the number of sessions of the whole program. The interventions were delivered in a variety of ways. The most commonly used format was face-to-face or group. Two studies delivered the intervention by talking with women on the telephone (Cheng et al., 2016),(Ngai et al., 2015). Yang 2019 (Yang et al., 2019) and Zhao 2018 (Zhao, 2018) conducted the intervention on a popular Chinese smartphone APP named WeChat, with all sessions recorded and uploaded to the platform. Half of the studies integrated interventions into an existing health education program or routine care. With respect to the fidelity of implementation, only two studies (Leung and Lam, 2012; Ngai et al., 2015) reported detailed information regarding supervision of the intervention, with intervention sessions videotaped and reviewed (Leung and Lam, 2012; Ngai et al., 2015). Detailed information is listed in Table 2.

The most commonly employed therapeutic approaches included cognitive behavioral (CBT, seven studies), psychoeducation (PE, seven studies), interpersonal therapy (IPT, three studies), mindfulness (two 


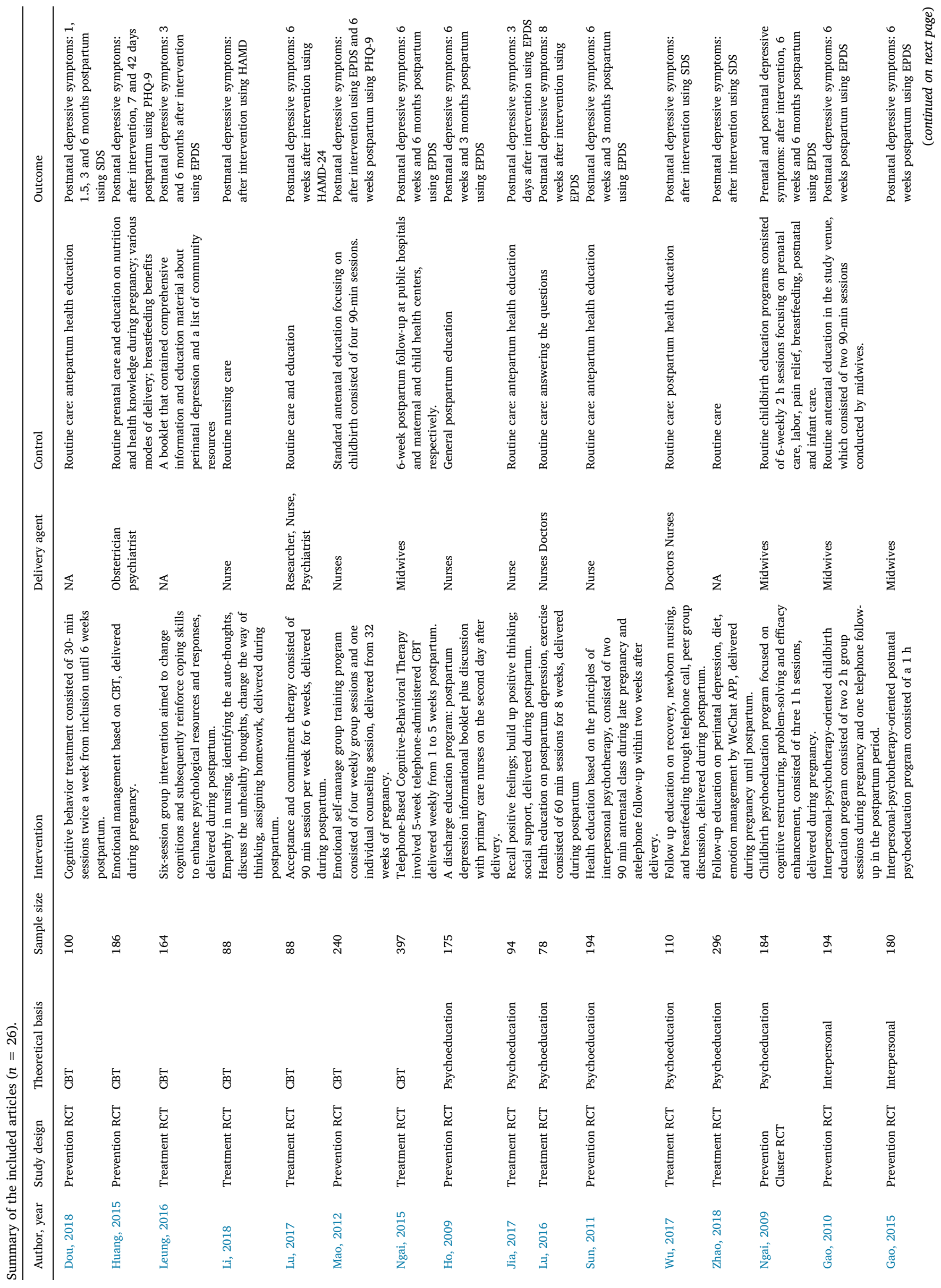




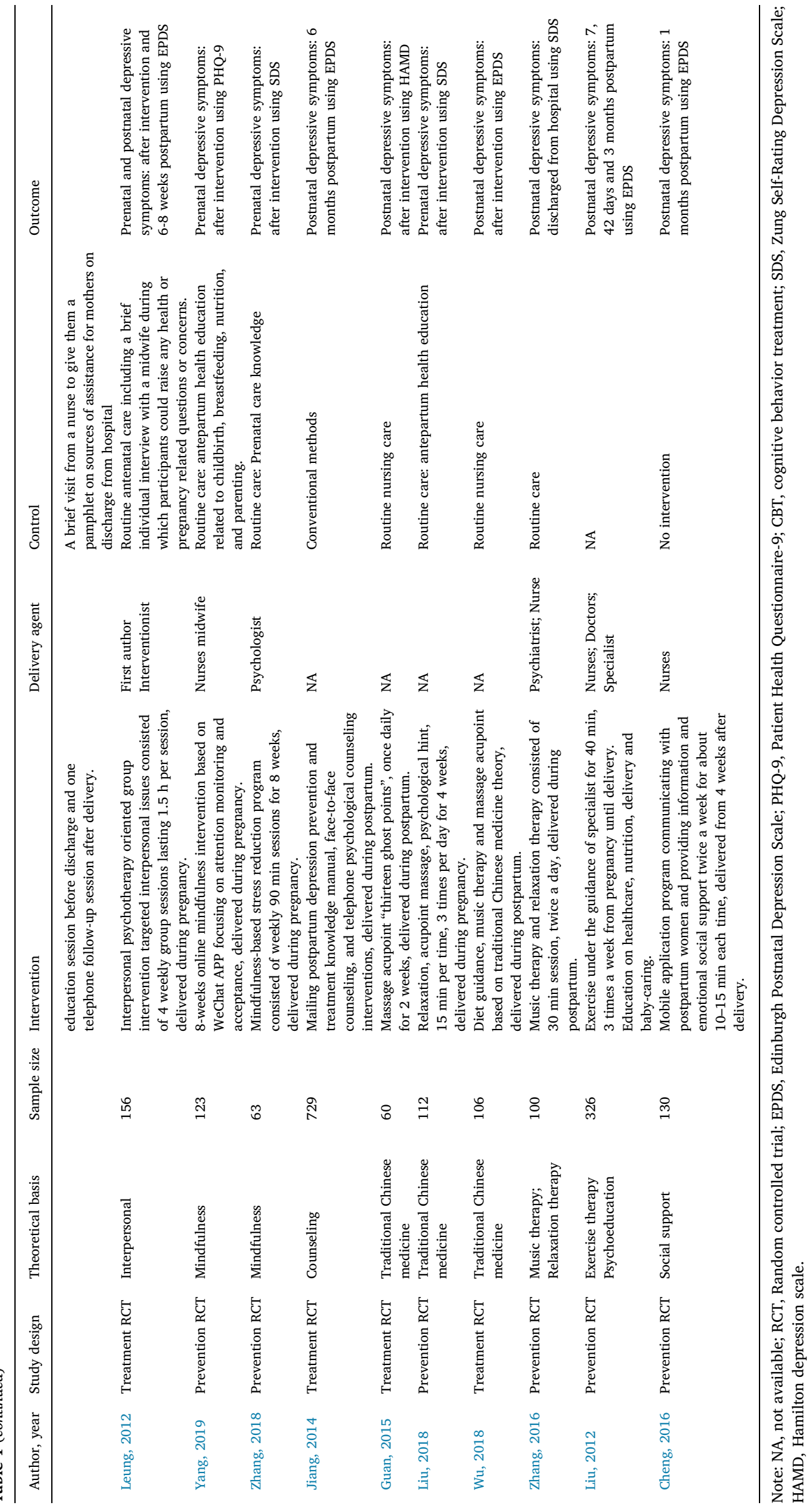


Table 2

Information of intervention delivery and delivery agent $(n=26)$.

\begin{tabular}{|c|c|c|c|c|c|c|c|c|c|c|}
\hline Author, year & $\begin{array}{l}\text { Intervention delivery } \\
\text { Integration }\end{array}$ & Technology & Location & Format & Duration & Fidelity & $\begin{array}{l}\text { Delivery agent } \\
\text { Profession }\end{array}$ & Qualification & Training & Supervision \\
\hline Gao, 2010 & $\begin{array}{l}\text { Integrated into hospital } \\
\text { routine childbirth education } \\
\text { sessions }\end{array}$ & $\begin{array}{l}\text { Face-to-face } \\
\text { Telephone }\end{array}$ & hospital & Group & 6 weeks & NA & Midwives & NA & Yes & Yes \\
\hline Gao, 2015 & $\begin{array}{l}\text { Integrated into hospital } \\
\text { discharge education }\end{array}$ & $\begin{array}{l}\text { Face-to-face } \\
\text { Telephone }\end{array}$ & hospital & Individual & 2 weeks & NA & Midwives & NA & NA & NA \\
\hline Guan, 2015 & Integrated into routine care. & Face-to-face & hospital & Individual & 2 weeks & NA & NA & NA & NA & NA \\
\hline Ho, 2009 & $\begin{array}{l}\text { Integrated into hospital } \\
\text { discharge education }\end{array}$ & Face-to-face & hospital & Individual & 1 day & NA & Nurses & NA & NA & NA \\
\hline Huang, 2015 & $\begin{array}{l}\text { Integrated into routine } \\
\text { prenatal care and education }\end{array}$ & Face-to-face & hospital & NA & 6 weeks & NA & $\begin{array}{l}\text { Obstetrician } \\
\text { psychiatrist }\end{array}$ & NA & NA & NA \\
\hline Jia, 2017 & Integrated into routine care. & Face-to-face & hospital & Group & NA & NA & Nurse & NA & NA & NA \\
\hline Jiang, 2014 & Integrated into hospital visits & $\begin{array}{l}\text { Mail } \\
\text { Face-to-face } \\
\text { Telephone }\end{array}$ & Home visits & Individual & NA & NA & NA & NA & NA & NA \\
\hline Leung, 2012 & $\begin{array}{l}\text { Integrated into a group } \\
\text { community-based family } \\
\text { centered parenting program }\end{array}$ & Face-to-face & $\begin{array}{l}\text { Maternal and Child } \\
\text { Health Center }\end{array}$ & Group & 4 weeks & Yes & $\begin{array}{l}\text { First author, } \\
\text { Interventionist }\end{array}$ & Yes & Yes & NA \\
\hline Li, 2018 & Integrated into routine care. & Face-to-face & hospital & Individual & NA & NA & Nurse & NA & NA & NA \\
\hline Mao, 2012 & Integrated into hospital visits & Face-to-face & hospital & Group & 4 weeks & NA & Nurses & NA & Yes & NA \\
\hline Wu, 2018 & Integrated into routine care. & Face-to-face & hospital & Individual & NA & NA & NA & NA & NA & NA \\
\hline Zhang, 2016 & Integrated into routine care. & Face-to-face & hospital & Individual & NA & NA & Psychiatrist, Nurse & NA & NA & NA \\
\hline Ngai, 2009 & $\begin{array}{l}\text { Integrated into routine } \\
\text { childbirth education program }\end{array}$ & Face-to-face & hospital & NA & 3 weeks & NA & Midwives & NA & Yes & NA \\
\hline Cheng, 2016 & NA & Telephone & hospital & Individual & 4 weeks & NA & Nurses & NA & Yes & NA \\
\hline Dou, 2018 & NA & Face-to-face & $\begin{array}{l}\text { Community health } \\
\text { care center }\end{array}$ & Individual & NA & NA & NA & NA & NA & NA \\
\hline Leung, 2016 & NA & Face-to-face & hospital & Group & 6 weeks & NA & NA & NA & NA & NA \\
\hline Liu, 2012 & NA & Face-to-face & hospital & Individual & NA & NA & $\begin{array}{l}\text { Nurses; Doctors; } \\
\text { Specialist }\end{array}$ & NA & NA & NA \\
\hline Liu, 2018 & NA & Face-to-face & hospital & Individual & NA & NA & NA & NA & NA & NA \\
\hline Lu, 2016 & NA & Face-to-face & hospital & Individual & 8 weeks & NA & Nurses Doctors & NA & NA & NA \\
\hline Lu, 2017 & NA & Face-to-face & hospital & NA & 6 weeks & NA & $\begin{array}{l}\text { Researcher, Nurse, } \\
\text { Psychiatrist }\end{array}$ & Yes & Yes & NA \\
\hline Ngai, 2015 & NA & Telephone & hospital & Individual & 5 weeks & Yes & Midwives & Yes & Yes & Yes \\
\hline Sun, 2011 & NA & $\begin{array}{l}\text { Face-to-face } \\
\text { Telephone }\end{array}$ & hospital & Group & NA & NA & Nurse & NA & NA & NA \\
\hline Wu, 2017 & NA & $\begin{array}{l}\text { Face-to-face } \\
\text { Telephone }\end{array}$ & hospital & Individual & NA & NA & Doctors Nurses & NA & NA & NA \\
\hline Yang, 2019 & NA & Mobile APP & hospital & Individual & 8 weeks & NA & Nurses midwife & NA & Yes & NA \\
\hline Zhang, 2018 & NA & Face-to-face & hospital & Group & 8 weeks & NA & Psychologist & NA & NA & NA \\
\hline Zhao, 2018 & NA & Mobile APP & hospital & Individual & NA & NA & NA & NA & NA & NA \\
\hline
\end{tabular}

Note: NA, not available.

studies) and person-centered counseling (one study, combined counseling with education). Among cognitive strategies, the commonest elements were identifying thoughts, behaviors, and cognitive restructuring. Among behavioral theory-based interventions, the predominant elements included problem solving, relaxation techniques and emotional regulation. Interpersonal strategies included communication skills and inciting social support. Caregiver coping was the most frequently reported element among parental skills-based strategies and birth procedures were most common psychoeducational component. The therapeutic elements comprising these interventions were heterogeneous and overlapped across different interventions. Other strategies not based on any established psychological theories included traditional Chinese practices (Liu (2018): acupoint massage, education and emotion release therapy; Wu (2018): acupoint massage, music therapy and diet nursing; Guan (2015): acupoint massage, music therapy and education), social support (one study), music therapy (one study, combined exercise with relaxation therapy) and exercise (one study, combined exercise with psychoeducation). The strategies included many non-specific elements such as prompting social support, involvement of family, active listening, involvement of significant others and so on. The most commonly used traditional Chinese practice was acupoint massage. Description of principles and rationale behind these interventions has been detailed in Fig. 2 and Appendix Table A4.

The summary measure corresponded to a strong overall effect size of
0.81 (95\% CI: -1.03 to $-0.58, P<0.001$ ), with five individual studies showing no significant difference in the effect size (Fig. 3). The overall evidence, however, presented substantial heterogeneity $\left(\mathrm{I}^{2}=91.12 \%\right.$, $P<0.001, Q=282.36$ ). Sensitivity analysis did not reveal any changes in the pooled effect size when individual study was removed from the meta-analysis. The effectiveness of these interventions $(n=10)$ remained significant (effect size: $-0.87,95 \%$ CI: -1.49 to $-2.73, \mathrm{I}^{2}=97.45 \%$ ) at follow-up (from 7 days to 6 months).

A series of subgroup analyses were conducted to ascertain differences in effect sizes among a priori defined groups of interventions (Appendix Table A5). High quality studies (Gao et al., 2010; Gao et al., 2015; Leung and Lam, 2012; Mao et al., 2012; Ngai et al., 2009; Ngai et al., 2015; Yang et al., 2019) yielded weaker effect sizes and performed better on heterogeneity measures than their counterparts. There was a significant difference in the effect sizes of different theoretical orientations, with exercise $(n=1)$ showing the largest $(-2.49,95 \% \mathrm{CI}$ : -3.26 to -1.71$)$ and interpersonal therapy $(n=3)$ the smallest ( -0.22 , 95\%CI: -0.48 to 0.03$)$. Though the size effect of treatment studies was higher than that of prevention studies, no statistical difference was found $\left(\chi^{2}=1.65, p=0.2\right)$. And no difference of effect size was found between interventions delivered by specialists and nonspecialists. Multivariate meta-regression was used to assess differences in effect sizes of subgroups of studies with different theoretical orientations, while accounting for quality of the studies, and employing 
Specific therapeutic ingredients $(\mathrm{N}=26)$

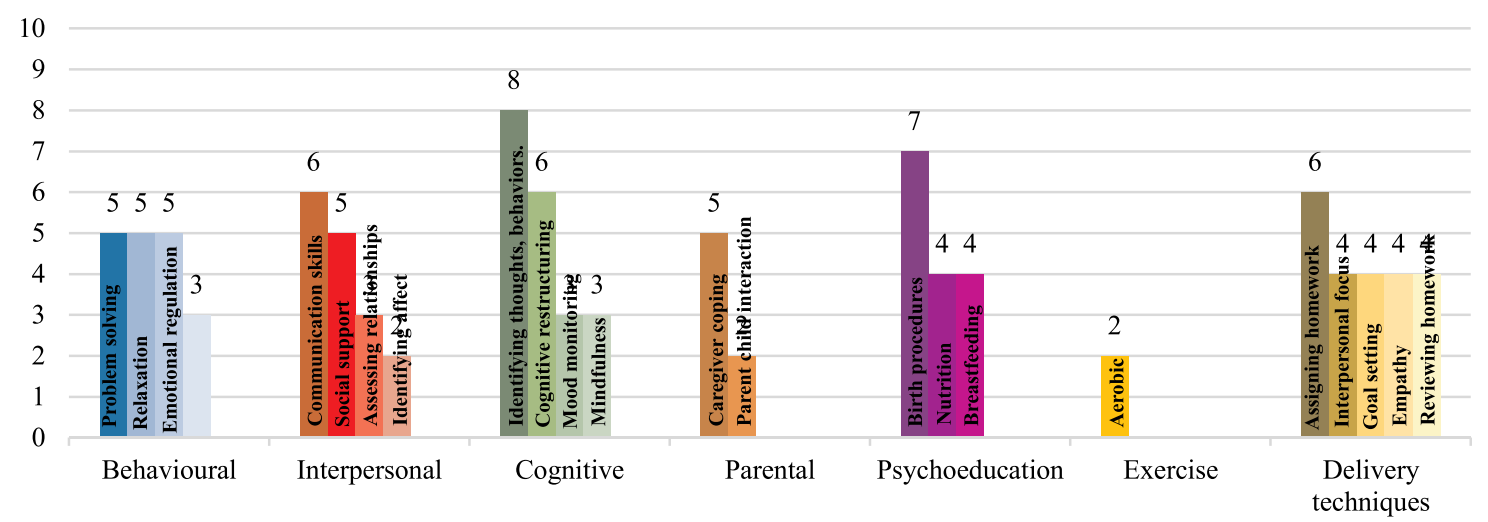

(a). Specific therapeutic ingredients of the included studies.

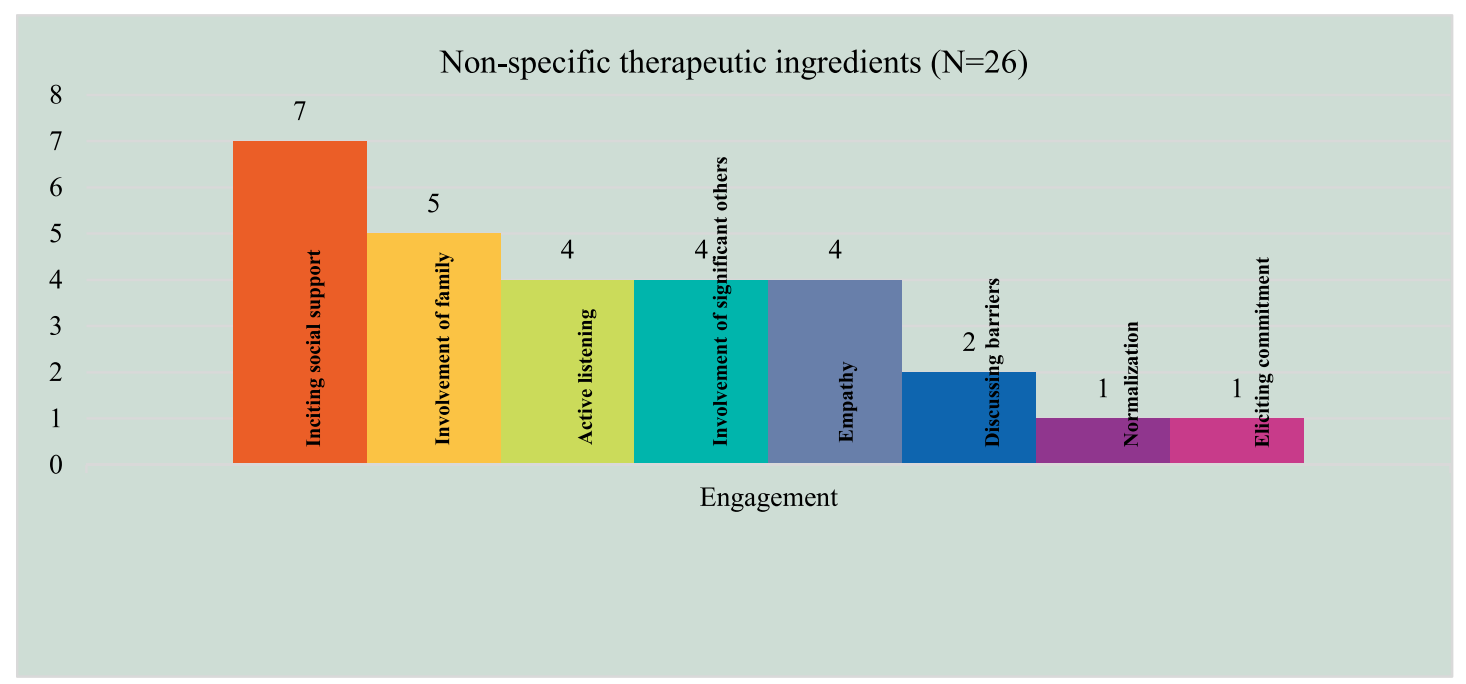

(b). Non-specific therapeutic ingredients of the included studies.

Fig. 2. (a). Specific therapeutic ingredients of the included studies. (b). Non-specific therapeutic ingredients of the included studies.

exercise-based therapy as a reference group. It yielded a significant model $(P<0.001)$ that explained $69 \%$ of variation in heterogeneity in the effect size of studies, where exercise-based therapy yielded the highest effect size, followed by traditional Chinese practice, counseling, music therapy, social support, psychoeducation, cognitive behavioral therapy, mindfulness and interpersonal therapy. Details were shown in Appendix Fig. A1 \& Appendix Table A6. When the analysis was restricted to psychotherapies including CBT, IPT, PE and mindfulness, no significant differences in effect sizes were noted $(P>0.05)$ (Appendix Fig. A1 \& Appendix Table A7). Maternal age did not account for variation in heterogeneity and effect sizes among the included trials $(\beta=0.06 ; P=0.35)$.

The result demonstrated that most RCT studies (73.1\%) included in the meta-analysis are of low quality. Visualization of funnel plot (Fig. 4) and assessment of Egger's regression statistic $(P=0.98)$ did not reveal any significant publication bias. The highest proportion of unclear risk of bias was exhibited in blinding of participants and personnel (24 studies). While five studies were rated as having a high risk of bias in reporting of incomplete outcome data. Detailed ratings of risk of bias have been presented in Appendix Fig. A2.

\section{Disscussion}

To the best of our knowledge, this is the first systematic review to provide an overview of psychosocial interventions, including traditional Chinese practices, for perinatal depression in China. The studies included in this review varied in the form, duration, theoretical orientation and delivery-agent of the interventions. Despite the diversity, it can be concluded that psychosocial interventions are relatively effective in reducing perinatal depressive symptoms. This result is consistent with the findings of other recent global reviews of evidence in the area (Dennis and Dowswell, 2013).

The analyses exhibited the highest effect size for exercise-based intervention, followed by psychological therapies embedded in traditional Chinese practices. This may indicate a cultural preference for interventions based on physical activity rather than conventional 'talking therapies'. However, these analyses may not present a true picture of the real treatment effects of these interventions, which may be a reflection of the quality and numbers of studies. There was only one intervention pertaining to exercise (Liu et al., 2012) and three to traditional Chinese practices (Guan et al., 2015; Liu et al., 2018; $\mathrm{Wu}, 2018)$. Besides, all the four above-mentioned studies were poorly designed according to the Cochrane risk of bias tool. Though classified as exercise-based intervention, the study (Liu et al., 2012) actually combined psychoeducation, which surely will exaggerate the size effect of exercise. In comparison, CBT (Mao et al., 2012; Ngai et al., 2015) and IPT based (Gao et al., 2010; Gao et al., 2015; Leung and Lam, 2012) studies showed low risk of bias and thus giving more precise estimates 


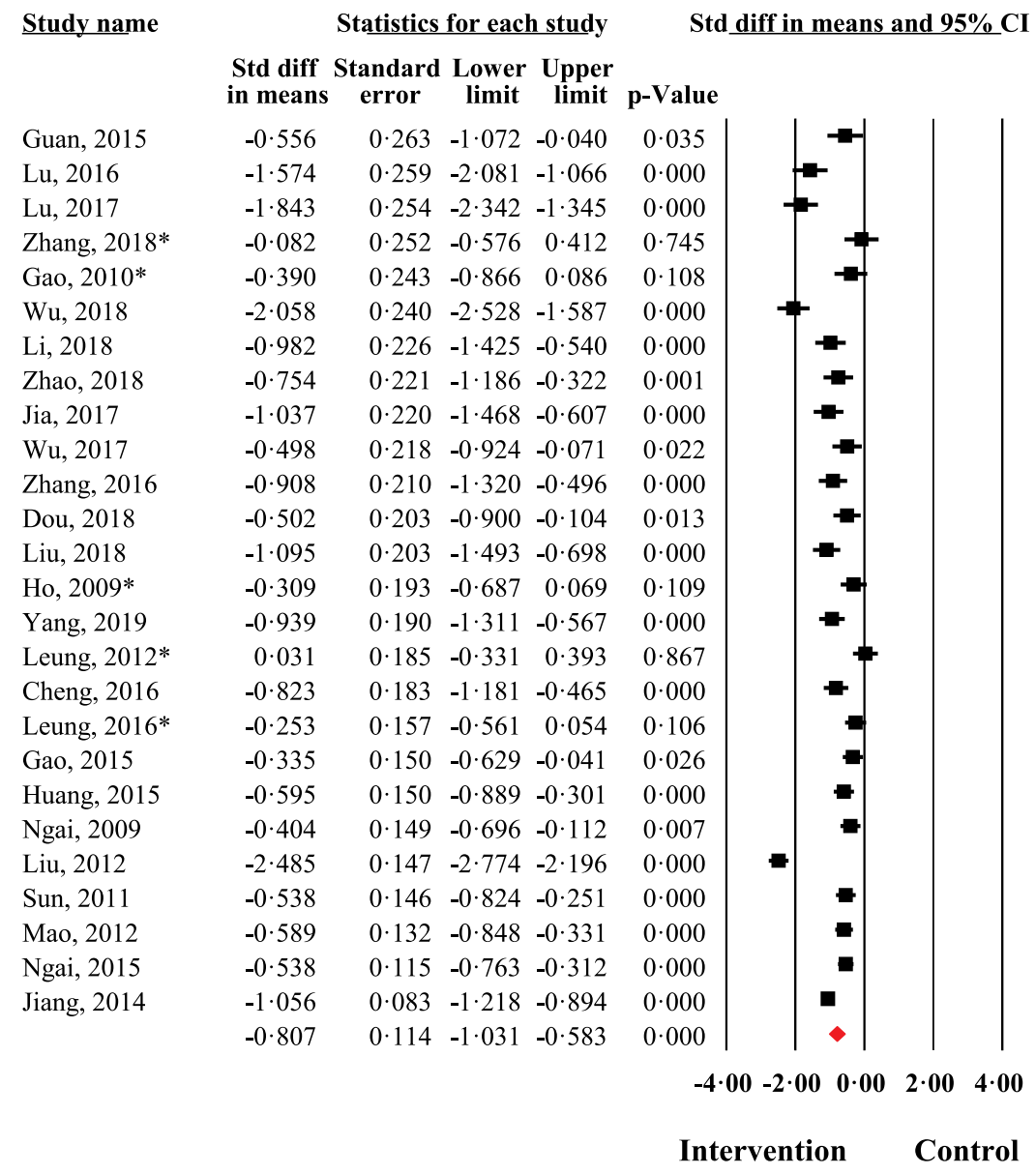

Fig. 3. Meta-analysis of psychosocial interventions of perinatal depression in women in China Note: * represents no significance was found $(p<0.1)$.

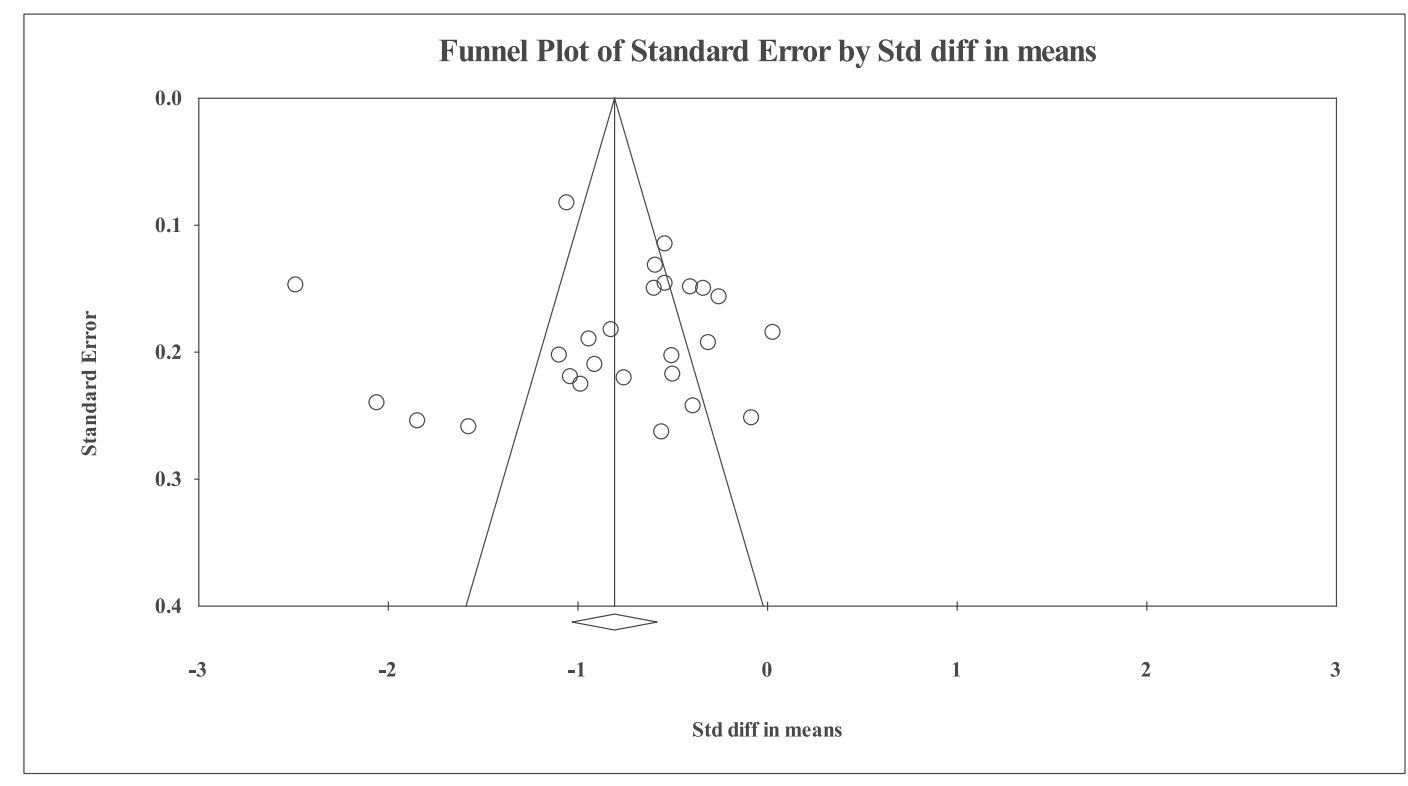

Fig. 4. Funnel plot. 
of treatment effects. Furthermore, interventions classified as traditional Chinese practices also combined other non-specific elements such as support and relaxation. Therefore, it is difficult to identify the sole effectiveness of these traditional Chinese practices. However, traditional Chinese practices in the management of perinatal depression should be an area of interest. For example, acupuncture, a traditional Chinese treatment, has been shown to significantly reduce postpartum depressive symptoms (Li et al., 2019). Thus, the role of traditional medicine as an adjunct to conventional approaches should be explored further and could be an important area for future research. Though classified as counseling and music therapy, Jiang (2014) and Zhang (2016) actually used multiple interventions in their studies. This may exaggerate the size effect and lead a bias to the result.

In the subgroup analyses, high quality studies yielded a weaker effect size than their low quality counterparts. A large proportion of studies included in this review were rated as low quality and tended to overestimate treatment effect sizes. Small-scale trials lacking proper randomization procedures contribute to selection bias and systematic differences between the intervention and placebo arms. Similar biases are associated with poor or no allocation concealment because allocation to intervention and control groups can be related to prognosis and responsiveness to treatment (Kunz et al., 2007). Future trials should focus on removing these potential sources of biases. The subgroup analyses also demonstrated that the effect of interventions delivered by non-specialists was comparable to that by specialists, which is consistent with other literature reports (Liu et al., 2017). No significant difference was found between the size effect of treatment and prevention studies. However, the result should be interpreted with caution. Participants undergoing treatment interventions have higher scores on depression screening instruments at baseline than the counterparts in preventive interventions. Thus, the former group experiences a larger decrease in their scale scores post-intervention, reflecting higher effect size estimates. In this review, several studies employed only screening instruments such as the EPDS to classify intervention recipients as having depression. The process of diagnoses should be done using diagnostic interviews based on DSM/ICD criteria for diagnosis or SCID. The use of screening instruments for diagnosis without employing a diagnostic interview can add potential bias in the meta-analysis.

It is notable that almost all studies in this review delivered their interventions in hospitals in urban areas of China. However, perinatal depression is more prevalent in underdeveloped regions and associated with poor socioeconomic and living conditions (Nisar et al., 2019). This result indicated that more research should be done on how to bridge the urgent need of mental health care in rural areas and the shortage of medical human resource. It has been proven that mental health interventions delivered by non-specialist under supervision are more beneficial than routine care and can reduce the disease burden of perinatal depression (Liu et al., 2017). Though half studies in this review reported integrating their interventions into existing services, few reported the process, cost and scale-up strategies. Studies in other LMICs proved that maternal mental health interventions can be added to existing health care services at little additional cost (Richter et al., 2017). Based on the above evidence, task shifting from mental health specialists to the community healthcare system, which was successfully demonstrated in many studies from LMICs (Rahman et al., 2013), could be a potential way forward in integration of mental health interventions and services into existing healthcare system in China.

The application of technology could be another way to improve access to mental health care. According to a recent systematic review (Ashford et al., 2016), computer- or web- based interventions could be a promising approach for accessing treatment for perinatal depression. In this review, two studies (Yang et al., 2019; Zhao, 2018) delivered mindfulness interventions through a popular Chinese mobile application named WeChat and both reported a significant positive result. However, adherence to intervention and quality control could limit the effectiveness of computer- or web-based interventions. Also, given that perinatal depression is more prevalent in under-developed regions, technological solutions must ensure equity for those who do not have access to this technology.

\section{Limitation}

There are some limitations in this review. Firstly, the evidence in this review is of moderate to low quality and therefore, should be interpreted with caution. The majority of the trials had high risk of bias with poor randomization and allocation concealment procedures. Secondly, some of the trials were inadequately powered and tended to overestimate effect sizes as demonstrated by a wide confidence interval for standard mean differences for those ten follow-up data. Thirdly, the implications of this review is limited in China as we only include psychosocial interventions on perinatal depression in China. Lastly, we did not find any statistical heterogeneity based on different assessment tools for assessment of depressive symptoms among the intervention recipients in different studies. Nonetheless, use of different psychometric instruments with different psychometric properties introduces methodological heterogeneity in meta-analysis. Therefore, these results should be interpreted with caution.

\section{Conclusion}

This review indicates that psychosocial interventions, particularly those involving psychoeducational and cognitive behavioral elements, are effective in reducing perinatal depressive symptoms. Traditional Chinese practices and exercise may add to the effectiveness of interventions. However, future high quality RCTs are required to supplement the evidence. Concurrently, strategies to scale-up effective interventions should be further developed and evaluated in a range of settings to reduce the treatment gap for perinatal depression.

\section{Contributors}

Juan Yin, Atif Rahman and Xiaomei Li conceived and designed the study; Anum Nisar and Juan Yin searched, screened and did the data extraction of the English studies; Yan Guo and Wenli Qi searched, screened and did the data extraction of the Chinese studies; Ahmed Waqas and Duolao Wang did the meta-analysis; Juan Yin first draft the paper and all the authors revised and approved it.

\section{Funding}

This study was supported by the Chinese Nursing Association (ZHKY201809). The funder of the study had no role in study design, data collection, data analysis, data interpretation, or writing of the report. The corresponding author had full access to all the data in the study and had final responsibility for the decision to submit for publication.

\section{Declaration of Competing Interest}

None.

\section{Acknowledgement}

We would like to thank the Chinese Nursing Association for supporting our research. 


\section{Appendix}

Figs. A1 and A2.

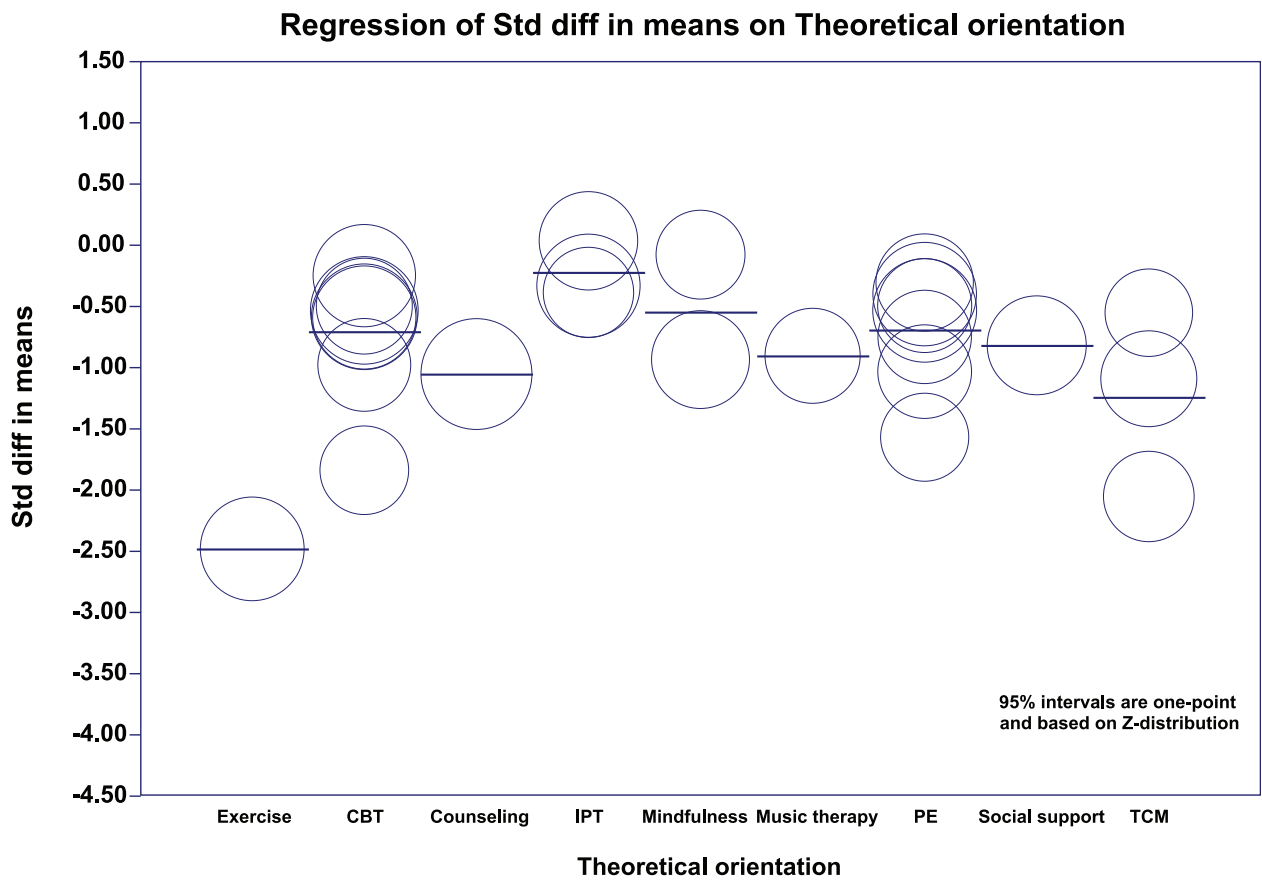

Fig. A1. Meta-regression analysis for theoretical orientation.

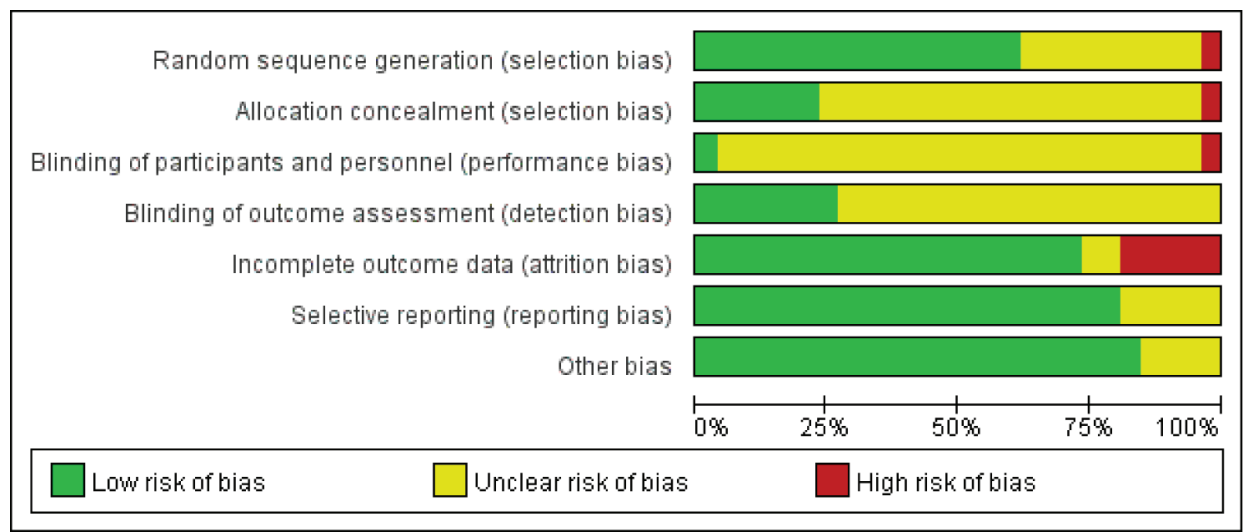

(a) Review authors' judgements about each risk of bias item presented as percentages across all included studies.

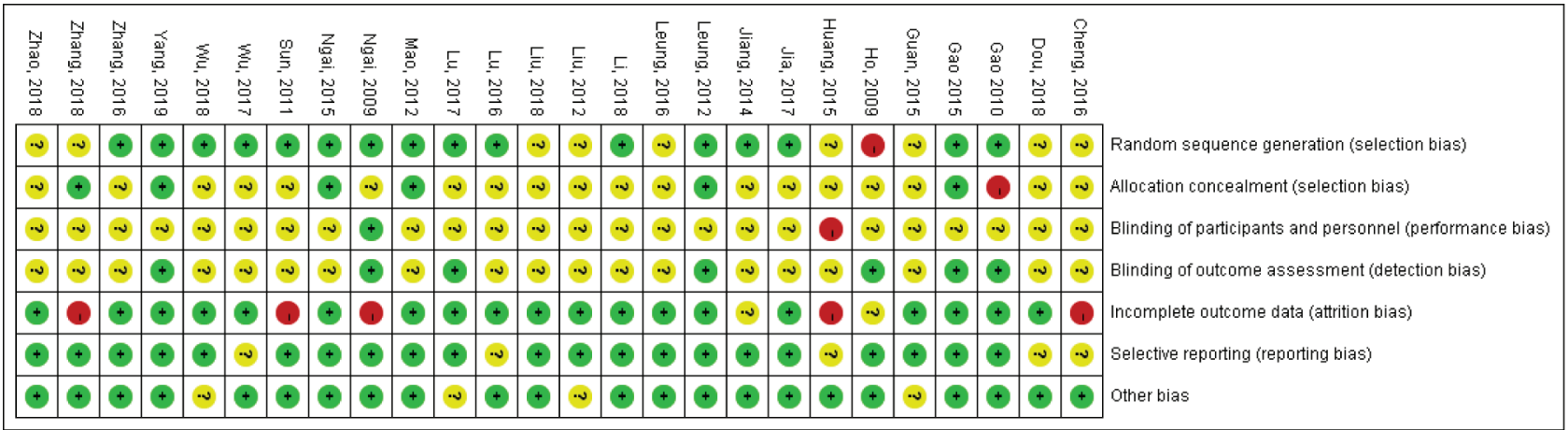

(b) Risk of bias items for each included study.

Fig. A2. Risk of bias. 
Tables A1,A2,A3,A4,A5,A6,A7,A8,A9,A10.

Table A1

Search strategy.

Search strategy in English databases

(Perinatal[ti/ab] OR maternal[ti/ab] OR mother*[ti/ab] OR pregnancy[ti/ab] OR pregnant[ti/ab] OR intrapartum[ti/ab] OR postpartum[ti/ab] OR prenatal[ti/ab] OR postnatal[ti/ab] OR antenatal[ti/ab] OR antepartum [ti/ab]) AND (depression[ti/ab] OR depressive[ti/ab] OR depress*[ti/ab] OR "mental health" [ti/ab]) AND (China OR Chinese OR Guangxi OR "inner Mongolia" OR Ningxia OR Tibet OR Xizang OR Xinjiang OR Heilongjiang OR Jilin OR Liaoning OR Hebei OR Shanxi OR Shandong OR Shaanxi OR Gansu OR Qinghai OR Sichuan OR Hubei OR Hunan OR Henan OR Anhui OR Zhejiang OR Jiangsu OR Guangdong OR Jiangxi OR Fujiang OR Guizhou OR Yunnan OR Hainan OR Han OR Hui OR Mongolia OR Zhuang) AND (trial[ti/ab] OR RCT[ti/ab] OR randomized-controlled[ti/ab] OR intervention[ti/ab] OR controlled-trial[ti/ab] OR effectiveness[ti/ab] OR efficacy[ti/ab])
Search strategy in Chinese databases

1. China National Knowledge Infrastructure (CNKI)

$(\mathrm{TI}=$ 围产期 $\mathrm{OR} \mathrm{TI}=$ 产妇 $\mathrm{OR} \mathrm{TI}=$ 妊娠 $\mathrm{OR} \mathrm{TI}=$ 孕妇 $\mathrm{OR} \mathrm{TI}=$ 孕期 $\mathrm{OR} \mathrm{TI}=$ 产前 $\mathrm{OR} \mathrm{TI}=$ 产后 $\mathrm{OR}$ $\mathrm{TI}=$ 分娩前 $\mathrm{OR} \mathrm{TI}=$ 分娩后 $\mathrm{OR} \mathrm{TI}=$ 产裖期 $) \mathrm{AND}(\mathrm{TI}=$ 抑郁 $\mathrm{OR} \mathrm{TI}=$ 精神 $\mathrm{OR} \mathrm{TI}=$ 心理 $) \mathrm{AND}$

$(\mathrm{AB}=$ 试验 $\mathrm{OR} \mathrm{AB}=\mathrm{RCT} \mathrm{OR} \mathrm{AB}=$ 随机对照 $\mathrm{OR} \mathrm{AB}=$ 干预 $\mathrm{OR} \mathrm{AB}=$ 对照 $\mathrm{OR} \mathrm{AB}=$ 效果 $)$

2. China National Knowledge Infrastructure (CNKI)

$(\mathrm{TI}=$ 围产期 $\mathrm{OR} \mathrm{TI}=$ 产妇 $\mathrm{OR} \mathrm{TI}=$ 妊娠 $\mathrm{OR} \mathrm{TI}=$ 孕妇 $\mathrm{OR} \mathrm{TI}=$ 孕期 $\mathrm{OR} \mathrm{TI}=$ 产前 $\mathrm{OR} \mathrm{TI}=$ 产后 $\mathrm{OR}$

$\mathrm{TI}=$ 分娩前 $\mathrm{OR} T \mathrm{TI}=$ 分娩后 $\mathrm{OR} \mathrm{TI}=$ 产裖期 $) \mathrm{AND}(\mathrm{TI}=$ 抑郁 $\mathrm{OR} \mathrm{TI}=$ 精神 $\mathrm{OR} \mathrm{TI}=$ 心理 $) \mathrm{AND}$

$(\mathrm{AB}=$ 试验 $\mathrm{OR} \mathrm{AB}=\mathrm{RCT} \mathrm{OR} \mathrm{AB}=$ 随机对照 $\mathrm{OR} \mathrm{AB}=$ 干预 $\mathrm{OR} \mathrm{AB}=$ 对照 $\mathrm{OR} \mathrm{AB}=$ 效果 $)$

3. VIP Database for Chinese Technical Periodicals

$(\mathrm{M}=$ 围产期 $\mathrm{OR} \mathrm{M}=$ 产妇OR $\mathrm{M}=$ 妊娠 $\mathrm{OR} \mathrm{M}=$ 㭆妇 $\mathrm{OR} \mathrm{M}=$ 㭆期 $\mathrm{OR} \mathrm{M}=$ 产前 $\mathrm{OR} \mathrm{M}=$ 产后 $\mathrm{OR}$

$M=$ 分娩前 OR $M=$ 分娩后 OR $M=$ 产裖期) AND ( $M=$ 抑郁 OR $M=$ 精神OR $M=$ 心理) AND

$(M=$ 试验 OR $M=$ RCT OR $M=$ 随机对照 $O R M=$ 干预 $O R M=$ 对照 $O R M=$ 效果)

4. Wan Fang Database

Title or Key words:((围产期 OR 产妇OR 妊娠 OR 孕妇 OR 孕期 OR 产前 OR 产后 OR 分娩前 OR 分娩后 OR 产裖期) AND (抑郁 OR 精神OR 心理) AND (试验 OR RCT OR 随机对照 OR 干预 OR 对照 OR 效果))

Table A2

Definitions of therapeutic techniques employed in psychosocial interventions.

\begin{tabular}{|c|c|c|}
\hline & Name of Skill & Definition of skill \\
\hline 1. & Involvement of family & The family members are involved in the intervention. \\
\hline 2. & Involvement of significant other & The significant other or spouse is involved in the intervention. \\
\hline 3. & Active listening & The skillful listens to the speaker with full concentration to understand what is being said [1]. \\
\hline 4. & Collaboration & Working with others \\
\hline 5. & Inciting social support & Providing insight of how others can provide help or support [2]. \\
\hline 6. & Case management & Planning, facilitating and coordination of different options regarding the patient [3]. \\
\hline 7. & Normalization & To communicate that the person's experiences also happen to other people [4]. \\
\hline 8. & eliciting commitment & Motivating the client to take active part in intervention. \\
\hline 9. & Discussing advantages & Identifying advantages to take the intervention. \\
\hline 10. & Discussing barriers & Identifying difficulties to take the intervention. \\
\hline 11. & Identifying affect & Identifying feeling or emotion [5]. \\
\hline 12. & identifying and eliciting social support & Providing consideration of how others could change their behavior to offer the person help or support [6]. \\
\hline 13. & Communication skills & $\begin{array}{l}\text { These are set of skills which improve the dissemination, reception and exchange of information, opinions or ideas } \\
\text { making sure that the intended message is completely understood by those involved [7]. }\end{array}$ \\
\hline 14. & Assertiveness training & To train people for effective communication without being passive or aggressive. \\
\hline 15. & Assessing relationships & To assess the relationships with people around. \\
\hline 16. & Problem solving & To solve a problem by carefully defining problem and weighing different options to solve the problem. \\
\hline 17. & Relaxation & To apply various techniques for relaxation. \\
\hline 18. & Awarding positive behavior & Applying different methods to encourage recurrence of a positive behavior [8]. \\
\hline 19. & Exposure & $\begin{array}{l}\text { Confronting previously avoided objects, situations, unwanted thoughts or feelings while not avoiding or escaping from } \\
\text { it [9]. }\end{array}$ \\
\hline 20. & Emotional regulation & Tendency to manage and responding to emotional experience [10]. \\
\hline 21. & Stress management & May involve a variety of techniques that do not target a specific behavior but seek to reduce anxiety and stress [6]. \\
\hline 22. & Decision making & Process of making choices by identifying decision, gathering information, and assessing alternative resolutions [11]. \\
\hline 23. & self-monitoring & The person keeps a record of one's own behavior [6]. \\
\hline 24. & Delay awards & A process of deferring initial reward for a better reward later [12]. \\
\hline 25. & $\begin{array}{l}\text { Caregiver coping (e.g., management skills for the } \\
\text { parents of children) }\end{array}$ & Mechanism through which the caregiver manages the stress [13]. \\
\hline 26. & $\begin{array}{l}\text { Parent-child Interaction Coaching (e.g., positive } \\
\text { 1-on-1, attending to children modeling, etc) }\end{array}$ & The parent applies a new skill with the child and the therapist provides immediate feedback [14]. \\
\hline 27. & Birth procedures & Knowledge about different ways of giving birth [15]. \\
\hline 28. & $\begin{array}{l}\text { Specific health areas of children (e.g., nutrition, } \\
\text { breastfeeding, SRH, etc) }\end{array}$ & If the intervention targeted the specific dimensions of health areas in children. \\
\hline 29. & Nutrition & Education regarding recommended nutrition practices. \\
\hline 30. & Breastfeeding & Education regarding recommended breastfeeding practices. \\
\hline 31. & Sexual behavior & Avoidance of risky sexual behaviors. \\
\hline 32. & $\begin{array}{l}\text { Identifying thoughts, behaviors, and their links (e.g., } \\
\text { identifying negative thoughts, thought diary, etc.) }\end{array}$ & Realizing what thoughts cross one's mind by number of ways [16]. \\
\hline 33. & $\begin{array}{l}\text { Cognitive restructuring (e.g., reattribution, weighing } \\
\text { evidence, logical questioning, etc.) }\end{array}$ & Identifying and disputing maladaptive thoughts [2]. \\
\hline 34. & Distraction & Paying attention to some other stimuli rather than the unhelpful thoughts [17]. \\
\hline 35. & Self-talk & Use of self-instruction and self-encouragement to support action [6]. \\
\hline 36. & Self-praise & To boast one's self esteem by expressing approval or admiration [18]. \\
\hline 37. & Mood monitoring & Paying attention toward one's mood states by means of different methods [19]. \\
\hline 38. & Mindfulness & Paying attention towards experiences in the present moment within body and mind and accepting the happenings [20]. \\
\hline 39. & Self-awareness & Conscious awareness of becoming the object of one's own awareness [21]. \\
\hline 40. & Aerobics & $\begin{array}{l}\text { Aerobic exercise also known as "cardio" exercises include running, swimming, walking, hiking, aerobics classes, } \\
\text { dancing, cross country skiing, and kickboxing. }\end{array}$ \\
\hline
\end{tabular}


Table A2 (continued)

\begin{tabular}{|c|c|c|}
\hline & Name of Skill & Definition of skill \\
\hline 41. & Non-aerobic exercise & $\begin{array}{l}\text { Anaerobic ("without oxygen") exercise is any physical activity that causes you to be quickly out of breath, like sprinting } \\
\text { or lifting a heavy weight. }\end{array}$ \\
\hline 42. & Motivational enhancement & To increase internal motivation in order to make long lasting change [22]. \\
\hline 43. & Praise & Praising for positive behavior or accomplishment. \\
\hline 44. & Role play & Performing role of a person in a situation [23]. \\
\hline 45. & Behavioral contracting & $\begin{array}{l}\text { Agreement of a contract specifying behavior to be performed so that there is a written record of the person's resolution } \\
\text { witnessed by another [6]. }\end{array}$ \\
\hline 46. & Assigning homework & Assigning tasks pertaining to interventions, to be performed at home. \\
\hline 47. & Interpersonal focus & Focus on maintaining relationships with other people [24]. \\
\hline 48. & Behavioral experiments & To test out the negative thoughts and re-evaluate underlying beliefs by performing an action [25]. \\
\hline 49. & Motivational interviewing & $\begin{array}{l}\text { Prompting the person to provide self-motivating statements and evaluation of their own behavior to minimize } \\
\text { resistance [6]. }\end{array}$ \\
\hline 50. & Direct suggestions & Providing directions of how to act, behave or handle a situation $[26,27]$ \\
\hline 51. & Goal setting & Identifying an aim or goal to achieve in a session or therapy [28]. \\
\hline 52. & Giving sick role & $\begin{array}{l}\text { Assigning role of a sick person to the participant, to understand the circumstances, particular rights and responsibilities } \\
\text { of those who are ill. }\end{array}$ \\
\hline 53. & Empathy & To understand and share other's feeling or situation [29]. \\
\hline 54. & Macronutrients & Food groups needed in large amounts $[30]$. \\
\hline 55. & Micronutrient & Food groups needed in small amounts [30]. \\
\hline 56. & Eating behaviors & The food choices and eating practices [31], \\
\hline 57. & Alcohol use & Education about minimal use and harms of alcohol misuse. \\
\hline 58. & Substance misuse & Harmful use of substances for non-medical purposes [32]. \\
\hline
\end{tabular}

References

1. Rogers, C.R. and R.E. Farson, Active listening. 1957: Industrial Relations Center of the University of Chicago.

2. Chambless, D.L. and S.D. Hollon, Defining empirically supported therapies. Journal of consulting and clinical psychology, $1998.66(1):$ p. 7.

3. Marshall, M., et al., Case management for people with severe mental disorders. The Cochrane database of systematic reviews, 2000(2): p. CD000050-CD000050.

4. Dovis, S., et al., Can motivation normalize working memory and task persistence in children with attention-deficit/hyperactivity disorder? The effects of money and computergaming. Journal of abnormal child psychology, 2012. 40(5): p. 669-681.

5. Dube, S., Enchantments of modernity: empire, nation, globalization. 2012: Routledge.

6. Abraham, C. and S. Michie, A taxonomy of behaviour change techniques used in interventions. Health psychology, 2008. 27(3): p. 379.

7. Baran, S.J., E. McDonald, and J. Engberg, Introduction to mass communication: Media literacy and culture. 2004: McGraw-Hill.

8. Cregor, M., The building blocks of positive behaviour. teaching tolerance, 2008. 34(4): p. 18-21.

9. Forsyth, J.P., V. Barrios, and D.T. Acheson, Exposure therapy and cognitive interventions for the anxiety disorders: overview and newer third-generation perspectives, in Handbook of exposure therapies. 2007, Elsevier. p. 61-108.

10. Rolston, A. and E. Lloyd-Richardson, What is emotion regulation and how do we do it? Cornell Research Program on Self-Injury and Recovery.[on-line].[cit. 201722-09] Available at: http://www.selfinjury.bctr.cornell.edu/perch/resources/what-is-emotion-regulationsinfo-brief.pdf. Google Scholar, 2017.

11. Janis, I.L. and L. Mann, Decision making: A psychological analysis of conflict, choice, and commitment. 1977: free press.

12. Metcalfe, J. and W. Mischel, A hot/cool-system analysis of delay of gratification: dynamics of willpower. Psychological review, 1999. $106(1):$ p. 3.

13. Zeiss, A.M., et al., Self-efficacy as a mediator of caregiver coping: Development and testing of an assessment model. Journal of clinical Geropsychology, 1999. 5(3): p. 221-230.

14. McNeil, C.B. and T.L. Hembree-Kigin, Parent-child interaction therapy. 2010: Springer Science \& Business Media.

15. Thompson, R. and Y.D. Miller, Birth control: to what extent do women report being informed and involved in decisions about pregnancy and birth procedures? BMC pregnancy and childbirth, 2014. 14(1): p. 62.

16. Longmore, R.J. and M. Worrell, Do we need to challenge thoughts in cognitive behaviour therapy? Clinical psychology review, 2007. 27(2): p. 173-187.

17. Fennell, M.J. and J.D. Teasdale, Effects of distraction on thinking and affect in depressed patients. British Journal of Clinical Psychology, 1984. 23(1): p. 65-66.

18. Abdel-Khalek, A.M., INTRODUCTION TO THE PSYCHOLOGY OF SELF-ESTEEM. SELF-ESTEEM: p. 1.

19. Swinkels, A. and T.A. Giuliano, The measurement and conceptualization of mood awareness: Monitoring and labeling one's mood states. Personality and social psychology bulletin, 1995. 21(9): p. 934-949.

20. Langer, E.J., Mindfulness. 1989: Addison-Wesley/Addison Wesley Longman. 88

21. Morin, A., Self-awareness part 1: Definition, measures, effects, functions, and antecedents. Social and personality psychology compass, 2011. 5(10): p. 807-823. 22. Miller, W.R., Motivational enhancement therapy manual: A clinical research guide for therapists treating individuals with alcohol abuse and dependence. 1995: DIANE Publishing.

23. Van Ments, M., The effective use of role-play: Practical techniques for improving learning. 1999: Kogan Page Publishers.

24. Leary, M.R. and R.F. Baumeister, The need to belong: Desire for interpersonal attachments as a fundamental human motivation, in Interpersonal Development. 2017, Routledge. p. 57-89.

25. Rouf, K., et al., Devising effective behavioural experiments. Oxford guide to behavioural experiments in cognitive therapy, 2004: p. 21-58.

26. Rossi, E.L. and K.L. Rossi, What is a suggestion? The neuroscience of implicit processing heuristics in therapeutic hypnosis and psychotherapy. American Journal of Clinical Hypnosis, 2007. 49(4): p. 267-281.

27. Podikunju-Hussain, S., Working with Muslims: Perspectives and suggestions for counseling. Vistas: Compelling perspectives on counseling, 2006: p. 103-106.

28. Locke, E.A. and G.P. Latham, A theory of goal setting \& task performance. 1990: Prentice-Hall, Inc.

29. Chinsky, J.M. and J. Rappaport, Brief critique of the meaning and reliability of" accurate empathy" ratings. Psychological Bulletin, $1970.73(5):$ p. 379.

30. Hadigan, C.M., et al., Assessment of macronutrient and micronutrient intake in women with anorexia nervosa. International Journal of Eating Disorders, 2000. 28(3): p. 284-292.

31. Turconi, G., et al., Eating habits and behaviours, physical activity, nutritional and food safety knowledge and beliefs in an adolescent Italian population. Journal of the American College of Nutrition, 2008. 27(1): p. 31-43.

32. Lingford-Hughes, A., S. Welch, and D. Nutt, Evidence-based guidelines for the pharmacological management of substance misuse, addiction and comorbidity: recommendations from the British Association for Psychopharmacology. Journal of Psychopharmacology, 2004. 18(3): p. 293-335. 


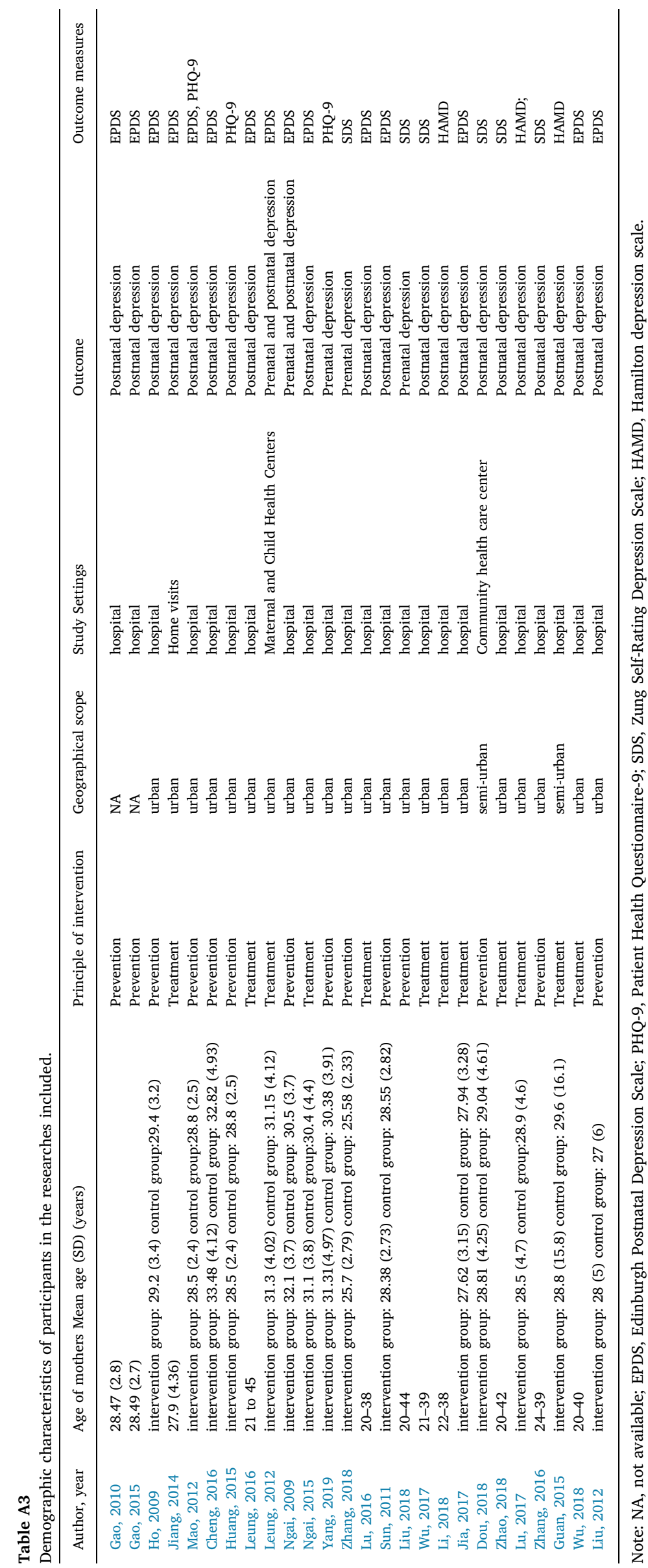


Table A4

Scope and taxonomy of interventions.

\begin{tabular}{|c|c|c|c|}
\hline Author year & Type & Major elements & Elements \\
\hline \multirow[t]{6}{*}{ Gao, 2010} & Prevention & Engagement & Active listening, inciting social support \\
\hline & & Interpersonal skills & Identifying and eliciting social support, communication skill, assessing relationships \\
\hline & & Behavior coping & Problem solving, stress management \\
\hline & & Parenting skill & Caregiver coping, parent-child interaction coaching \\
\hline & & Psychoeducation & Birth procedure, nutrition, breastfeeding, sexual behavior \\
\hline & & Techniques used by delivery agent & Motivational enhancement, role play, interpersonal focus, direct suggestion, goal setting \\
\hline \multirow[t]{6}{*}{ Gao, 2015} & Prevention & Engagement & Active listening, inciting social support \\
\hline & & Interpersonal skill & Identifying affect, identifying and eliciting social support, Communication skill, assessing relationships \\
\hline & & Behavior coping & Problem solving \\
\hline & & Parenting skill & Parent-child interaction coaching \\
\hline & & Psychoeducation & Breastfeeding \\
\hline & & Techniques used by delivery agent & Interpersonal focus \\
\hline Ho, 2009 & Prevention & Cognitive coping & Mood monitoring, self-awareness \\
\hline \multirow[t]{6}{*}{ Mao, 2012} & Prevention & Engagement & Involvement of significant others, inciting social support \\
\hline & & Interpersonal skill & Communication skill \\
\hline & & Behavior coping & Problem solving, relaxation, self-monitoring \\
\hline & & Psychoeducation & Birth procedure \\
\hline & & Cognitive coping & Identifying thoughts, cognitive restructuring, self-talk, self-praise, mood monitoring, self-awareness \\
\hline & & Techniques used by delivery agent & Role paly, assigning homework, interpersonal focus, reviewing homework \\
\hline Jiang, 2014 & Treatment & - & - \\
\hline \multirow[t]{4}{*}{ Cheng, 2016} & Prevention & Engagement & Empathy \\
\hline & & Interpersonal skills & Identifying and eliciting social support \\
\hline & & Psychoeducation & Birth procedure, breast feeding \\
\hline & & Techniques used by delivery agent & Empathy \\
\hline \multirow[t]{5}{*}{ Huang, 2015} & Prevention & Engagement & Involvement of family, inciting social support \\
\hline & & Interpersonal skills & Identifying and eliciting social support \\
\hline & & Behavior coping & Relaxation, exposure, emotional regulation, eliciting social support \\
\hline & & Psychoeducation & Birth procedure \\
\hline & & Cognitive coping & Cognitive restructuring \\
\hline \multirow[t]{2}{*}{ Leung, 2016} & Treatment & Cognitive coping & Identifying thoughts, cognitive restructuring, distraction \\
\hline & & techniques used by delivery agent & Assigning homework \\
\hline \multirow[t]{2}{*}{ Leung, 2012} & Treatment & Interpersonal skills & Communication skills, assertiveness training, assessing relationship \\
\hline & & techniques used by delivery agent & Role play, assigning homework, interpersonal focus, reviewing homework, goal setting \\
\hline \multirow[t]{5}{*}{ Ngai, 2009} & Prevention & Behavior coping & Problem solving, stress management, decision making \\
\hline & & Reinforcement & Awarding positive behavior \\
\hline & & Parenting skill & Caregiver coping \\
\hline & & Cognitive coping & Cognitive restructuring \\
\hline & & Techniques used by delivery agent & Goal setting \\
\hline \multirow[t]{6}{*}{ Ngai, 2015} & Treatment & Interpersonal skills & Communication skills \\
\hline & & Behavior coping & Problem solving, exposure, stress management, decision making \\
\hline & & Reinforcement & Awarding positive behavior \\
\hline & & Parenting skill & Caregiver coping \\
\hline & & Cognitive coping & Identifying thoughts, cognitive restructuring \\
\hline & & Techniques used by delivery agent & Goal setting \\
\hline \multirow[t]{5}{*}{ Yang, 2019} & Prevention & Engagement & Discussing barriers to treatment \\
\hline & & Interpersonal skills & Identifying affect \\
\hline & & Behavior coping & Relaxation, stress management \\
\hline & & Cognitive coping & Identifying thoughts, mood monitoring, mindfulness \\
\hline & & Techniques used by delivery agent & Assigning homework, reviewing homework \\
\hline Zhang, 2018 & Prevention & Engagement & Discussing barriers to treatment \\
\hline & & Cognitive coping & Mindfulness \\
\hline & & Exercise & Aerobics \\
\hline & & Techniques used by delivery agent & Assigning homework, reviewing homework \\
\hline Lu, 2016 & Treatment & Engagement & Involvement of family, active listening, empathy \\
\hline & & Exercise & Others \\
\hline & & Techniques used by delivery agent & Empathy \\
\hline Sun, 2011 & Prevention & Engagement & Inciting social support \\
\hline & & Interpersonal skills & Identifying and eliciting social support, communication skills \\
\hline & & Behavior coping & Stress management \\
\hline & & Parenting skill & Caregiver coping \\
\hline Liu, 2018 & Prevention & - & - \\
\hline Wu, 2017 & Treatment & Parenting skill & Caregiver coping \\
\hline & & Psychoeducation & Birth procedure, breast feeding \\
\hline Li, 2018 & Treatment & Engagement & Active listening, empathy \\
\hline & & Cognitive coping & Identifying thoughts, cognitive restructuring \\
\hline & & Techniques used by delivery agent & Assigning homework, empathy \\
\hline Jia, 2017 & Treatment & Engagement & Involvement of family, involvement of significant others \\
\hline & & Behavior coping & Emotional regulation \\
\hline & & Psychoeducation & Birth procedure \\
\hline & & Cognitive coping & Identifying thoughts \\
\hline Dou, 2018 & Prevention & Engagement & Inciting social support \\
\hline & & Behavior coping & Relaxation \\
\hline & & Cognitive coping & Identifying thoughts \\
\hline Zhao, 2018 & Treatment & Engagement & Involvement of family \\
\hline
\end{tabular}


Table A4 (continued)

\begin{tabular}{|c|c|c|c|}
\hline Author year & Type & Major elements & Elements \\
\hline & & Behavior coping & Emotional regulation \\
\hline & & Psychoeducation & Nutrition \\
\hline \multirow[t]{3}{*}{ Lu, 2017} & Treatment & Engagement & Empathy, normalization, eliciting commitment \\
\hline & & Cognitive coping & Identifying thoughts, mindfulness \\
\hline & & Techniques used by delivery agent & Empathy \\
\hline Zhang, 2016 & Prevention & Behavior coping & Relaxation \\
\hline Guan, 2015 & Treatment & - & - \\
\hline Wu, 2018 & Treatment & Psychoeducation & Nutrition \\
\hline \multirow[t]{3}{*}{ Liu, 2012} & Prevention & Engagement & Involvement of family \\
\hline & & Psychoeducation & Birth procedure, nutrition \\
\hline & & Exercise & Aerobics \\
\hline
\end{tabular}

Table A5

Subgroup analysis of the psychosocial interventions.

\begin{tabular}{|c|c|c|c|c|c|}
\hline Moderators & No of studies & Point estimate $(95 \% \mathrm{CI})$ & $\mathrm{I}^{2}$ & $\chi^{2}$ (Q statistic) & $\mathrm{P}$ \\
\hline \multicolumn{6}{|l|}{ Quality } \\
\hline High & 7 & $-0.45(-0.85$ to -0.05$)$ & $61.83 \%$ & 4.13 & 0.04 \\
\hline Low & 19 & $-0.94(-1.19$ to -0.69$)$ & $91.78 \%$ & & \\
\hline \multicolumn{6}{|l|}{ Scale } \\
\hline EPDS & 14 & $-0.83(-1.19$ to -0.48$)$ & $94.67 \%$ & 1.32 & 0.73 \\
\hline SDS & 6 & $-0.66(-0.93$ to -0.38$)$ & $60.28 \%$ & & \\
\hline HAMD & 3 & $-1.13(-1.84$ to -0.41$)$ & $84.67 \%$ & & \\
\hline PHQ-9 & 3 & $-0.68(-0.87$ to -0.48$)$ & $23.81 \%$ & & \\
\hline Theoretical orientation & & & & 29.17 & $<0.001$ \\
\hline CBT & 7 & $-0.72(-1.00$ to -0.43$)$ & $81.30 \%$ & & \\
\hline Psychoeducation & 7 & $-0.70(-0.98$ to -0.42$)$ & $73.72 \%$ & & \\
\hline TCM & 3 & $-1.24(-2.05$ to -0.40$)$ & $89.38 \%$ & & \\
\hline Interpersonal treatment & 3 & $-0.22(-0.48$ to 0.03$)$ & $31.46 \%$ & & \\
\hline Mindfulness & 2 & $-0.53(-1.37$ to 0.31$)$ & $86.43 \%$ & & \\
\hline Counseling & 1 & $-1.06(-1.79$ to -0.32$)$ & $0 \%$ & & \\
\hline Exercise & 1 & $-2.49(-3.26$ to -1.71$)$ & $0 \%$ & & \\
\hline Social support & 1 & $-0.82(-1.62$ to -0.02$)$ & $0 \%$ & & \\
\hline Music Therapy & 1 & $-0.90(-1.73$ to -0.08$)$ & $0 \%$ & & \\
\hline Specificity & & & & 0.11 & 0.74 \\
\hline Non-specificity & 7 & $-0.87(-1.14$ to -0.60$)$ & $74.66 \%$ & & \\
\hline specificity & 19 & $-0.78(-1.08$ to -0.49$)$ & $92.85 \%$ & & \\
\hline Scope of intervention & & & & 1.65 & 0.20 \\
\hline Treatment & 12 & $-0.97(-1.31$ to -0.63$)$ & $92.97 \%$ & & \\
\hline Prevention & 14 & $-0.67(-0.98$ to -0.36$)$ & $87.59 \%$ & & \\
\hline \multicolumn{6}{|l|}{ Elements of interventions } \\
\hline Engagement & & & & 0.78 & 0.38 \\
\hline No & 11 & $-0.69(-0.98$ to -0.40$)$ & $88.89 \%$ & & \\
\hline Yes & 15 & $-0.90(-0.99$ to -0.55$)$ & $92.74 \%$ & & \\
\hline Interpersonal skills & & & & 3.78 & 0.05 \\
\hline No & 17 & $-0.96(-1.29$ to -0.64$)$ & $92.65 \%$ & & \\
\hline Yes & 9 & $-0.53(-0.69$ to -0.37$)$ & $57.52 \%$ & & \\
\hline Behavioral coping & & & & 2.47 & 0.12 \\
\hline No & 14 & $-0.97(-1.37$ to -0.57$)$ & $94.26 \%$ & & \\
\hline Yes & 12 & $-0.60(-0.71$ to -0.48$)$ & $31.24 \%$ & & \\
\hline Reinforcement & & & & 0.77 & 0.39 \\
\hline No & 24 & $-0.84(-1.08$ to -0.59$)$ & $91.43 \%$ & & \\
\hline Yes & 2 & $-0.49(-0.67$ to -0.31$)$ & $0 \%$ & & \\
\hline Parenting skills & & & & 0.10 & 0.76 \\
\hline No & 19 & $-0.83(-1.04$ to -0.61$)$ & $85.23 \%$ & & \\
\hline Yes & 7 & $-0.75(-1.35$ to -0.15$)$ & $96.26 \%$ & & \\
\hline Psychoeducation & & & & 1.05 & 0.31 \\
\hline No & 16 & $-0.71(-0.93$ to -0.49$)$ & $85.02 \%$ & & \\
\hline Yes & 10 & $-0.96(-1.44$ to -0.47$)$ & $94.73 \%$ & & \\
\hline Cognitive coping & & & & 1.44 & 0.23 \\
\hline No & 14 & $-0.93(-1.30$ to -0.57$)$ & $93.61 \%$ & & \\
\hline Yes & 12 & $-0.65(-0.86$ to -0.44$)$ & $76.85 \%$ & & \\
\hline Delivery agents & & & & 0.41 & 0.52 \\
\hline Non-specialist* & 15 & $-0.89(-1.23$ to -.56$)$ & $93.26 \%$ & & \\
\hline Specialist & 5 & $-0.67(-1.26$ to -0.08$)$ & $90.45 \%$ & & \\
\hline
\end{tabular}

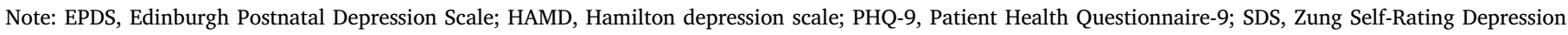
Scale; CBT, Cognitive behavior treatment; TCM, Traditional Chinese medicine.

* includes multidisciplinary teams with no specialists

includes multidisciplinary teams with at least one specialist 
Table A6

Meta-regression analyses for theoretical orientation of psychosocial therapies.

\begin{tabular}{|c|c|c|c|c|c|c|}
\hline Covariate & Coefficient & $S \cdot E$ & $\begin{array}{l}\text { 95\% CI } \\
\text { Lower }\end{array}$ & Upper & Z-value & $p$ \\
\hline Intercept & -2.37 & 0.39 & -3.13 & -1.60 & -6.05 & 0 \\
\hline Quality & -0.12 & 0.19 & -0.49 & 0.26 & -0.62 & 0.53 \\
\hline $\mathrm{CBT}$ & 1.74 & 0.37 & 1.01 & 2.47 & 4.67 & $<0.001$ \\
\hline Counseling & 1.43 & 0.47 & 0.51 & 2.34 & 3.06 & $<0.001$ \\
\hline IPT & 2.17 & 0.42 & 1.35 & 3.00 & 5.14 & $<0.001$ \\
\hline Mindfulness & 1.87 & 0.45 & 0.10 & 2.74 & 4.19 & $<0.01$ \\
\hline Music therapy & 1.58 & 0.51 & 0.59 & 2.57 & 3.12 & $<0.01$ \\
\hline Psychoeducation & 1.77 & 0.37 & 1.04 & 2.49 & 4.79 & $<0.001$ \\
\hline Social support & 1.66 & 0.49 & 0.69 & 2.63 & 3.36 & $<0.001$ \\
\hline TCM & 1.24 & 0.41 & 0.44 & 2.04 & 3.04 & $<0.01$ \\
\hline
\end{tabular}

$\mathrm{Q}=31.20, \mathrm{df}=8, \mathrm{p}=0.0001 ; \mathrm{R}^{2}=69 \% ; \mathrm{n}=26$ studies

Table A7

Meta-regression analyses for psychotherapies only.

\begin{tabular}{|c|c|c|c|c|c|c|}
\hline Covariate & Beta & $\begin{array}{l}\text { Standard } \\
\text { Error }\end{array}$ & $\begin{array}{l}\text { 95\% CI } \\
\text { Lower }\end{array}$ & Upper & Z-value & $\begin{array}{l}\text { 2-sided } \\
\text { P-value }\end{array}$ \\
\hline Intercept & -0.71 & 0.14 & -0.99 & -0.44 & -5.11 & 0 \\
\hline $\begin{array}{c}\text { Interpersonal } \\
\text { therapy }\end{array}$ & 0.49 & 0.26 & -0.02 & 0.99 & 1.88 & 0.06 \\
\hline Mindfulness & 0.16 & 0.31 & -0.44 & 0.77 & 0.53 & 0.60 \\
\hline Psychoeducation & 0.01 & 0.20 & -0.38 & 0.41 & 0.07 & 0.95 \\
\hline
\end{tabular}

$\mathrm{Q}=4.08, \mathrm{df}=3, p=0.2529 ; R^{2}=24 \%$

Table A8

Inter-coder agreement of the taxonomy of interventions.

\begin{tabular}{|c|c|c|c|c|c|c|}
\hline & $\mathrm{N}$ & Range & Minimum & Maximum & Mean & Std. Deviation \\
\hline Elements & 61 & 0.35 & 0.65 & 1.00 & 0.9924 & 0.04706 \\
\hline Valid N (listwise) & 61 & & & & & \\
\hline
\end{tabular}

Table A9

Inter-coder agreement of risk of bias.

\begin{tabular}{|c|c|c|c|c|c|c|}
\hline & $\mathrm{N}$ & Range & Minimum & Maximum & Mean & Std. Deviation \\
\hline bias & 7 & 0.16 & 0.84 & 1.00 & 0.9504 & 0.06591 \\
\hline Valid N (listwise) & 7 & & & & & \\
\hline
\end{tabular}

Table A10

PRISMA 2009 check list.

\begin{tabular}{|c|c|c|}
\hline Section/topic & \# & Checklist item \\
\hline \multicolumn{3}{|l|}{ Title } \\
\hline Title & 1 & Identify the report as a systematic review, meta-analysis, or both. \\
\hline \multicolumn{3}{|r|}{ ( } \\
\hline Structured summary & 2 & $\begin{array}{l}\text { Provide a structured summary including, as applicable: background; objectives; data sources; study eligibility criteria, participants, and } \\
\text { interventions; study appraisal and synthesis methods; results; limitations; conclusions and implications of key findings; systematic review } \\
\text { registration number. }\end{array}$ \\
\hline \multicolumn{3}{|r|}{ 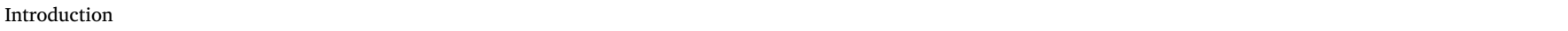 } \\
\hline Rationale & 3 & Describe the rationale for the review in the context of what is already known. \\
\hline Objectives & 4 & $\begin{array}{l}\text { Provide an explicit statement of questions being addressed with reference to participants, interventions, comparisons, outcomes, and } \\
\text { study design (PICOS). }\end{array}$ \\
\hline \multicolumn{3}{|r|}{$\begin{array}{l}\text { P } \\
\end{array}$} \\
\hline Protocol and registration & 5 & $\begin{array}{l}\text { Indicate if a review protocol exists, if and where it can be accessed (e.g., Web address), and, if available, provide registration information } \\
\text { including registration number. }\end{array}$ \\
\hline Eligibility criteria & 6 & $\begin{array}{l}\text { Specify study characteristics (e.g., PICOS, length of follow-up) and report characteristics (e.g., years considered, language, publication } \\
\text { status) used as criteria for eligibility, giving rationale. }\end{array}$ \\
\hline Information sources & 7 & $\begin{array}{l}\text { Describe all information sources (e.g., databases with dates of coverage, contact with study authors to identify additional studies) in the } \\
\text { search and date last searched. }\end{array}$ \\
\hline Search & 8 & Present full electronic search strategy for at least one database, including any limits used, such that it could be repeated. \\
\hline Study selection & 9 & $\begin{array}{l}\text { State the process for selecting studies (i.e., screening, eligibility, included in systematic review, and, if applicable, included in the meta- } \\
\text { analysis). }\end{array}$ \\
\hline
\end{tabular}


Table A10 (continued)

\begin{tabular}{|c|c|c|}
\hline Section/topic & \# & Checklist item \\
\hline Data collection process & 10 & $\begin{array}{l}\text { Describe method of data extraction from reports (e.g., piloted forms, independently, in duplicate) and any processes for obtaining and } \\
\text { confirming data from investigators. }\end{array}$ \\
\hline Data items & 11 & List and define all variables for which data were sought (e.g., PICOS, funding sources) and any assumptions and simplifications made. \\
\hline Risk of bias in individual studies & 12 & $\begin{array}{l}\text { Describe methods used for assessing risk of bias of individual studies (including specification of whether this was done at the study or } \\
\text { outcome level), and how this information is to be used in any data synthesis. }\end{array}$ \\
\hline Summary measures & 13 & State the principal summary measures (e.g., risk ratio, difference in means). \\
\hline Synthesis of results & 14 & $\begin{array}{l}\text { Describe the methods of handling data and combining results of studies, if done, including measures of consistency (e.g., } \mathrm{I}^{2} \text { ) for each } \\
\text { meta-analysis. }\end{array}$ \\
\hline Risk of bias across studies & 15 & Specify any assessment of risk of bias that may affect the cumulative evidence (e.g., publication bias, selective reporting within studies). \\
\hline Additional analyses & 16 & $\begin{array}{l}\text { Describe methods of additional analyses (e.g., sensitivity or subgroup analyses, meta-regression), if done, indicating which were pre- } \\
\text { specified. }\end{array}$ \\
\hline \multicolumn{3}{|r|}{ 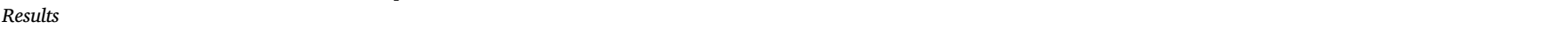 } \\
\hline Study selection & 17 & $\begin{array}{l}\text { Give numbers of studies screened, assessed for eligibility, and included in the review, with reasons for exclusions at each stage, ideally } \\
\text { with a flow diagram. }\end{array}$ \\
\hline Study characteristics & 18 & For each study, present characteristics for which data were extracted (e.g., study size, PICOS, follow-up period) and provide the citations. \\
\hline Risk of bias within studies & 19 & Present data on risk of bias of each study and, if available, any outcome level assessment (see item 12). \\
\hline Results of individual studies & 20 & $\begin{array}{l}\text { For all outcomes considered (benefits or harms), present, for each study: (a) simple summary data for each intervention group (b) effect } \\
\text { estimates and confidence intervals, ideally with a forest plot. }\end{array}$ \\
\hline Synthesis of results & 21 & Present results of each meta-analysis done, including confidence intervals and measures of consistency. \\
\hline Risk of bias across studies & 22 & Present results of any assessment of risk of bias across studies (see Item 15). \\
\hline \multicolumn{3}{|r|}{ 6he } \\
\hline Summary of evidence & 24 & $\begin{array}{l}\text { Summarize the main findings including the strength of evidence for each main outcome; consider their relevance to key groups (e.g., } \\
\text { healthcare providers, users, and policy makers). }\end{array}$ \\
\hline Limitations & 25 & $\begin{array}{l}\text { Discuss limitations at study and outcome level (e.g., risk of bias), and at review-level (e.g., incomplete retrieval of identified research, } \\
\text { reporting bias). }\end{array}$ \\
\hline Conclusions & 26 & Provide a general interpretation of the results in the context of other evidence, and implications for future research. \\
\hline \multicolumn{3}{|r|}{ ( } \\
\hline Funding & 27 & Describe sources of funding for the systematic review and other support (e.g., supply of data); role of funders for the systematic review. \\
\hline
\end{tabular}

\section{Reference}

Ashford, M.T., Olander, E.K., Ayers, S., 2016. Computer- or web-based interventions for perinatal mental health: a systematic review. J. Affect. Disord. 197, 134-146.

Bauer, A., Knapp, M., Parsonage, M., 2016. Lifetime costs of perinatal anxiety and depression. J. Affect. Disord. 192, 83-90.

Biaggi, A., Conroy, S., Pawlby, S., Pariante, C.M., 2016. Identifying the women at risk of antenatal anxiety and depression: a systematic review. J. Affect. Disord. 191, 62-77.

Cheng, H.Y., Huang, T.Y., Chien, L.Y., Cheng, Y.F., Chen, F.J., 2016. The effects of a mobile application social support program on postpartum perceived stress and depression. J. Nurs. (Chinese) 63, 52-60.

Dennis, C.L., Dowswell, T., 2013. Psychosocial and psychological interventions for preventing postpartum depression. The Cochrane database of systematic reviews, CD001134.

Dou, J., 2018. Preventive effect of perioperative psychological guidance on postpartum depression. Psychol. Doc. (Chinese) 24, 81-82.

Evans, J., Heron, J., Francomb, H., Oke, S., Golding, J., 2001. Cohort study of depressed mood during pregnancy and after childbirth. BMJ 323, 257-260.

Gao, L.L., Chan, S.W., Li, X., Chen, S., Hao, Y., 2010. Evaluation of an interpersonalpsychotherapy -oriented childbirth education programme for Chinese first-time childbearing women: a randomised controlled trial. Int. J. Nurs. Stud. 47, 1208-1216.

Gao, L.L., Xie, W., Yang, X., Chan, S.W., 2015. Effects of an interpersonal-psychotherapyoriented postnatal programme for Chinese first-time mothers: a randomized controlled trial. Int. J. Nurs. Stud. 52, 22-29.

Gelaye, B., Rondon, M.B., Araya, R., Williams, M.A., 2016. Epidemiology of maternal depression, risk factors, and child outcomes in low-income and middle-income countries. Lancet Psychiatry 3, 973-982.

Guan, L., Sun, J., Zheng, H., Pan, N., Shi, H., 2015. Evaluation on the effect of seven emotion theory of traditional Chinese medicine in nursing care of patients with postpartum depression. J. Sichuan Tradit. Chin. Med. (Chinese) 33, 172-175.

American College of Obstetricians and Gynecologists, 2018. Screening for perinatal depression. Committee opinion no. 757. Obstet Gynecol. 132, 1314-1316.

Herba, C.M., Glover, V., Ramchandani, P.G., Rondon, M.B., 2016. Maternal depression and mental health in early childhood: an examination of underlying mechanisms in low-income and middle-income countries. Lancet Psychiatry 3, 983-992.

Ho, S.M., Heh, S.S., Jevitt, C.M., Huang, L.H., Fu, Y.Y., Wang, L.L., 2009. Effectiveness of a discharge education program in reducing the severity of postpartum depression: a randomized controlled evaluation study. Patient Educ. Couns. 77, 68-71.

Huang, J., Li, H., Wang, J., Mao, H., Jiang, W., Zhou, H., Chen, S., 2015. Prenatal emotion management improves obstetric outcomes: a randomized control study. Int. J. Clin. Exp. Med. 8, 9667-9675.

Jia, D., Liang, Y., Tang, C., 2017. Effect of group positive experience on preventing postpartum depression. Chin. J. Mod. Nurs. (Chinese) 23, 1201-1204.
Jiang, L., Wang, Z.Z., Qiu, L.R., Wan, G.B., Lin, Y., Wei, Z., 2014. Psychological intervention for postpartum depression. J. Huazhong Univ. Sci. Technol. Med. Sci. (Chinese) 34, 437-442.

Kunz, R., Vist, G., Oxman, A.D., 2007. Randomisation to protect against selection bias in healthcare trials. The Cochrane database of systematic reviews, Mr000012.

Leung, S., Lee, A., Wong, D., Wong, C., Leung, K., Chiang, V., Yung, W., Chan, S., Chung, K., 2016. A brief group intervention using a cognitive-behavioral approach to reduce postnatal depressive symptoms: a randomised controlled trial. Hong Kong Med. J. (Chinese) 22, S4-S8.

Leung, S.S., Lam, T.H., 2012. Group antenatal intervention to reduce perinatal stress and depressive symptoms related to intergenerational conflicts: a randomized controlled trial. Int. J. Nurs. Stud. 49, 1391-1402.

Li, A., 2018. Effect of empathy nursing combined with cognitive behavior intervention on HAMD score and quality of life in patients with postpartum depression. Henan Med. Res. (Chinese) 27, 1326-1327.

Li, W., Yin, P., Lao, L., Xu, S., 2019. Effectiveness of Acupuncture Used for the Management of Postpartum Depression: A Systematic Review and Meta-Analysis. Biomed. Res. Int. 2019, 6597503.

Liu, H., Sun, G., Liu, Y., Fu, J., 2012. Observation on the clinical effect of health exercises and health education during pregnancy on the prevention of postpartum depression. Matern. Child Health Care China (Chinese) 27, 5851-5852.

Liu, S., Yan, Y., Gao, X., Xiang, S., Sha, T., Zeng, G., He, Q., 2017. Risk factors for postpartum depression among Chinese women: path model analysis. BMC Pregnancy Childbirth 17, 133.

Liu, Z., Na, L., Deng, Z., Shao, X., 2018. Effect of emotional release therapy in prenatal care on mental health, self-efficacy and parenting cognition of pregnant and puerpera. Nurs. Pract. Res. (Chinese) 15, 105-107.

Lu, D., Fan, J., 2017. Effect of routine nursing combined with Acceptance and Commitment Therapy on the depression mood, self efficacy and self-esteem of patients with postpartum depression. Sichuan Ment. Health (Chinese) 30, 253-255.

Lu, X., Chen, W., Wu, H., 2016. Effect of Roy adaptation model implementation of psychological comfort care in patients with postpartum depression. China Med. Herald (Chinese) 13, 168-171.

Mao, H.J., Li, H.J., Chiu, H., Chan, W.C., Chen, S.L., 2012. Effectiveness of antenatal emotional self-management training program in prevention of postnatal depression in Chinese women. Perspect. Psychiatr. Care 48, 218-224.

Ministry of Foreign Affairs, P. R. C., 2015. Report on China's Implementation of the Millennium Development Goals (2000-2015).

Naveed, S, Waqas, A, Amray, AN, et al., 2019. Implementation and effectiveness of nonspecialist mediated interventions for children with Autism spectrum disorder: a systematic review and metaanalysis. PLoS One 14 (11), e0224362.

Ngai, F.W., Chan, S.W., Ip, W.Y., 2009. The effects of a childbirth psychoeducation program on learned resourcefulness, maternal role competence and perinatal depression: a quasi-experiment. Int. J. Nurs. Stud. 46, 1298-1306.

Ngai, F.W., Wong, P.W., Leung, K.Y., Chau, P.H., Chung, K.F., 2015. The effect of 
telephone-based cognitive-behavioral therapy on postnatal depression: a randomized controlled trial. Psychother. Psychosom. 84, 294-303.

Nisar, A., Yin, J., Waqas, A., Xue, B., Wang, D., Rahman, A., Li, X., 2019. Prevalence of Perinatal Depression and its Determinants in Mainland China: A Systematic Review and Meta-Analysis (unpublished). Xi'an Jiaotong University, pp. 1-15.

Rahman, A., Fisher, J., Bower, P., Luchters, S., Tran, T., Yasamy, M.T., Saxena, S., Waheed, W., 2013. Interventions for common perinatal mental disorders in women in low- and middle-income countries: a systematic review and meta-analysis. Bull. World Health Organ. 91, 593-601I.

Richter, L.M., Daelmans, B., Lombardi, J., Heymann, J., Boo, F.L., Behrman, J.R., Lu, C., Lucas, J.E., Perez-Escamilla, R., Dua, T., Bhutta, Z.A., Stenberg, K., Gertler, P., Darmstadt, G.L., 2017. Investing in the foundation of sustainable development: pathways to scale up for early childhood development. Lancet North Am. Ed. 389, 103-118.

Singla, D.R., Kohrt, B.A., Murray, L.K., Anand, A., Chorpita, B.F., Patel, V., 2017. Psychological Treatments for the world: lessons from low- and middle-income countries. Ann. Rev. Clin. Psychol. 13, 149-181.

Sun, K., Gao, L., Li, Y., Gao, L., Luo, S., 2011. Effects of psychoeducation program on social support and symptomatology of depression among chinese first-time mothers. J. Sun Yat-sen Univ. (Chinese) 32, 90-95.

Weissman, M.M., Wickramaratne, P., Nomura, Y., Warner, V., Pilowsky, D., Verdeli, H.,
2006. Off spring of depressed parents: 20 years later. Am. J. Psychiatry 163, 1001-1008.

Woody, C.A., Ferrari, A.J., Siskind, D.J., Whiteford, H.A., Harris, M.G., 2017. A systematic review and meta-regression of the prevalence and incidence of perinatal depression. J. Affect. Disord. 219, 86-92.

Wu, D., 2018. Discussion on nursing intervention methods of traditional Chinese medicine syndrome differentiation of postpartum depression. Inner Mongolia Med. J. (Chinese) 50, 638-639.

Wu, H., 2017. Influence of continuous nursing on postpartum depression and quality of life in primiparae. China Modern Med. (Chinese) 24, 151-153.

Yang, M., Jia, G., Sun, S., Ye, C., Zhang, R., Yu, X., 2019. Effects of an online mindfulness intervention focusing on attention monitoring and acceptance in pregnant women: a randomized controlled trial. J. Midwifery Women's Health 64, 68-77.

Zhang, J.Y., Cui, Y.X., Zhou, Y.Q., Li, Y.L., 2018. Effects of mindfulness-based stress reduction on prenatal stress, anxiety and depression. Psychol. Health Med. 24, 51-58.

Zhang, Y., Zhou, M., Dang, W., Zhang, L., 2016. Factors affecting the mental health of puerperal women and their treatment strategies. J. Int. Psychiatry 43, 182-185.

Zhao, H., 2018. Effect of continuous nursing intervention based on WeChat platform on postpartum anxiety, depression and self-efficacy of parturients. Inner Mongolia Med. J. (Chinese) 50, 616-618. 